\title{
A MODEL TO REDUCE EARTHMOVING IMPACTS
}

\author{
Hassanean S. H. JASSIM (1) $1,2^{\star}$, Jan KRANTZ ${ }^{1}$, \\ Weizhuo LU (iD) 1 , Thomas OLOFSSON (ID) 1 \\ ${ }^{1}$ Division of Industrialized and Sustainable Construction, Department of Civil, Environmental \\ and Natural Resources Engineering, Lulea University of Technology, 97187 Luleå, Sweden \\ ${ }^{2}$ Department of Civil Engineering, College of Engineering, University of Babylon, 51002 Babylon, Iraq
}

Received 21 August 2019; accepted 17 December 2019

\begin{abstract}
Meeting increasingly ambitious carbon regulations in the construction industry is particularly challenging for earthmoving operations due to the extensive use of heavy-duty diesel equipment. Better planning of operations and balancing of competing demands linked to environmental concerns, costs, and duration is needed. However, existing approaches (theoretical and practical) rarely address all of these demands simultaneously, and are often limited to parts of the process, such as earth allocation methods or equipment allocation methods based on practitioners' past experience or goals. Thus, this study proposes a method that can integrate multiple planning techniques to maximize mitigation of project impacts cost-effectively, including the noted approaches together with others developed to facilitate effective decision-making. The model is adapted for planners and contractors to optimize mass flows and allocate earthmoving equipment configurations with respect to tradeoffs between duration, cost, $\mathrm{CO}_{2}$ emissions, and energy use. Three equipment allocation approaches are proposed and demonstrated in a case study. A rule-based approach that allocates equipment configurations according to hauling distances provided the best-performing approach in terms of costs, $\mathrm{CO}_{2}$ emissions, energy use and simplicity (which facilitates practical application at construction sites). The study also indicates that trucks are major contributors to earthmoving operations' costs and environmental impacts.
\end{abstract}

Keywords: earthmoving operations, optimization framework, optimum configuration, tradeoff duration, cost, emissions.

\section{Introduction}

Climate change poses significant threats to, among other things, human health (McMichael et al., 2006), economic development (Ciscar et al., 2011), and species survival (Fordham et al., 2012). To mitigate such threats, increasingly ambitious policies and regulations on carbon and other greenhouse gas (GHG) emissions are being introduced. Strategies such as the global Paris Agreement to limit global warming to under two degrees Celsius above pre-industrial temperatures (UNFCCC, 2015), various national carbon tax schemes ( $\mathrm{Lin} \& \mathrm{Li}, 2011$ ), and the European carbon trading scheme for energy generation and energy intensive industries (European Commission [EC], 2003) now form a complex legislative framework that attempts to deal with the problem. In line with this general picture, carbon reduction policies are increasingly being implemented within the construction industry. For instance, the Swedish Transport Administration is imposing carbon reduction goals on contractors delivering road projects, with the goal of a net zero carbon transport infrastructure no later than 2045 (Trafikverket, 2017). Generally, a number of solutions have been proposed to gradually mitigate these impacts in the construction sector, and these relate to advanced technologies for improving construction equipment performance and/or their fuel use.

Although there are promising alternatives to diesel, such as biofuels (Love \& Nejadhashemi, 2011) and diesel retrofit technologies (Kubsh, 2017) and electrified equipment, these are unlikely to become mainstream in the near future (Lajunen et al., 2018). This anticipated delay in the adoption of this technology might be related to the national and regional budgets required for companies to replace their current fleets, even though they are expected to serve for the next several years. Moreover, the efficiency and real useful life for hybrid engines working under different conditions in the field might not have been fully verified by

${ }^{*}$ Corresponding author. E-mail: hassanean.jassim@ltu.se 
equipment owners yet. Consequently, despite the availability of such technologies, some emissions reductions may still be achieved by using existing equipment more efficiently (Marshall et al., 2012), such as through increasing their utilization rates (Jassim et al., 2018a, 2018b; Jassim et al., 2019). This necessitates viewing items of equipment as interconnected components in a process, which in turn requires careful planning of earthmoving operations ( $\mathrm{Ahn}$ et al., 2009). Consequently, to avoid excessive emissions, the assessment of environmental impacts needs to be an integral part of project planning (Grann, 1997). Furthermore, accurate construction operation planning that also incorporates the selection of suitable equipment contributes to mitigating emissions and to cost savings (Szamocki et al., 2019).

Several studies have used various methods to evaluate the GHG emissions of construction equipment and operations (Avetisyan et al., 2011), and they have also emphasized the significant footprint of the project's planning stages in terms of mitigating the impact of construction equipment (Ahn et al., 2010; Zhang et al., 2014). There is, therefore, a need to identify and make available specific methods to assess emissions related to each construction subsector since this is considered an important step towards mitigating GHG emissions from the construction sector as a whole (Melanta et al., 2012). Despite this clear need, most assessments are currently conducted either during construction, or even after project completion (Dongier \& Lovei, 2006). Furthermore, comprehensive methods for assessing and reducing the GHG emissions of specific construction equipment and project operations in the planning phase are still lacking (Jassim et al., 2018b; Melanta et al., 2012). Methods that can assess activity impacts alongside the related resources are indispensable for confident planning, resource allocation, assessment, decision-making, and ultimately impact mitigation in this field (Jassim et al., 2018b).

A vital step towards encouraging stakeholders in the construction sector to consider the environmental impacts of their operations and equipment selection is linking this to their traditional targets. Specifically, construction managers and contractors have a major responsibility for equipment use on site, but reducing emissions is generally not a primary concern unless accompanied by reduced costs or shortened project duration (Jukic \& Carmichael, 2016). These targets were also considered as priority aims for planners within the parameters of setting out the plans for project execution. Developers also routinely select contractors offering the lowest bid rather than taking other factors into account (Ariaratnam et al., 2013). Although the aforementioned literature clearly signals the potential for reducing GHG emissions, further theoretical development is necessary to better enable implementation in earthmoving projects (González \& Echaveguren, 2012; Liu et al., 2013). First, to be of interest to contractors, GHG reduction measures should be practical both in terms of cost and project duration (Jukic \& Carmichael, 2016; Shi et al., 2013). Although Ahn et al. (2009) specifically acknowledged the need to explore the tradeoff between GHG emissions, costs, and duration when developing new methods, only a limited number of studies have considered those aspects in earthmoving projects (Ahn et al., 2009; B. Kim \& Y. Kim, 2016). Second, any methods developed should be comprehensive enough to encompass several components, or, indeed, the entire process (Akadiri et al., 2012). B. Kim and Y. Kim (2016) and Ahn et al. (2009) only considered the impact of different equipment configurations in small or hypothetical earthmoving cases under specific conditions.

The main objective of this study, therefore, is to propose a comprehensive model that will offer useful guidance for the optimum planning and assessment of earthmoving operations (what might be termed a 'cradle to grave' model) while considering cost, duration, and emissions from these operations at the activity level of a project. This is achieved through finding a mass haul balance and selecting optimum distances for hauling materials from cutting to filling areas, followed by equipment selection and performance estimations (cost, duration, energy use, and $\mathrm{CO}_{2}$ emissions) per functional unit and in total, and then proposing three approaches to support decision-making for earthmoving configuration allocations for each station and/or zone of earthmoving to ensure a reduction in the project's total impacts. The idea behind the proposed approaches is to find an uncomplicated way to facilitate a configuration allocation for the earthmoving project in the planning phase that will have minimized impacts, by highlighting a configuration based on mass hauling distances. The approach is demonstrated by an applied case study. The adopted approach reflects the effects of hauling distances on the impacts generated by each configuration selected for a specific job (i.e., quantity, destination, and equipment). In other words, an optimum configuration is allocated for hauling materials between two points (i.e., from cutting station to filling or dumping site) that might not remain the best choice if the hauling distances are, for example, changed to other destinations. The model will support planners, construction managers, and contractors in the pre-construction phase to assess and reduce the total impacts (cost, time, and $\mathrm{CO}_{2}$ emissions) of earthmoving operations from mass balance to configuration allocation. An additional objective is to identify the $\mathrm{CO}_{2}$ emissions and cost impacts for each item of earthmoving machinery (i.e. truck, excavator, and wheel loader) as a weighted ratio, in respect of total emissions and the cost of earthmoving operations over an entire project. This finding is also used to partially validate the adopted approach to configuration allocation as a proposed model by comparing it with impact ratios measured in previous studies. In addition, utility theory is used to demonstrate the validity of the adopted approach by showing a higher utility index for the configurations selected. Consequently, this study can also increase planners' and contractors' knowledge of significant mechanisms that must be considered in planning to mitigate the environmental impact of earthmoving operations while also, at the very least, 
not raising the minimum unit cost of execution. Therefore, this knowledge can also provide rational targets for stakeholders to consider energy use with related emissions calculations during the formulation of earthmoving plans.

The paper is structured as follows. First, a literature review of studies on earthmoving planning and assessment impacts of earthmoving equipment and its operation is presented. Then, the Planning, Simulation, Estimation, and Decision-making (PSED) model is presented with subsections to clarify the description. In the third section, the PSED model is demonstrated using a case study so that the results and findings of the study can be discussed, and a comparative validation shown. Finally, the conclusions and implications are summarized.

\section{Literature review}

Earthmoving operations have been identified as a major contributor to transport infrastructure project costs and to environmental impacts (Kim et al., 2012), mainly due to various uncertainties associated with these activities. Hence, improving such activities could produce major benefits for earthmoving projects. The current literature in this field has emphasized two approaches for planning and performing optimum earthmoving (Gwak et al., 2018), and these can be termed as: i) earth mass allocation methods (EMA), and ii) earthmoving equipment allocation methods (EEA). In addition, a few studies have also been done that relate to these two approaches, but which rather focus on measuring, assessing, and reducing emissions from earthmoving operations or the equipment used in them. Thus, the studies done in this field that relate to the scope of the present study can be divided into the two main categories noted above, each based on the topic which is emphasized.

\subsection{Earth mass allocation methods}

When considering this first theoretical approach to the problem, researchers have focused their efforts on minimizing the impacts of earthmoving operations by conducting optimum planning of mass distribution for onsite and offsite transport in infrastructure projects. Earthmoving typically consists of excavation (cutting) at locations where there is an excess of earth, dumping (filling) of that material at locations with an earth deficit, and the haulage of materials between those locations. A primary goal sought by planners is to balance the cut and fills as far as possible in the project so that dumping or sourcing materials outside the project is minimized or avoided altogether (Mawdesley et al., 2002). As such, this approach seeks the minimization of haul distances (or costs) in the earthmoving system, treated as a shortest path problem (Son et al., 2005). Beyond that, by efficiently matching the materials from the cut areas with the fill areas, the overall earthmoving costs of the project can be reduced (Gwak et al., 2018). This can be viewed as an allocation problem with the objective of optimizing the set of hauls between the cuts and fills with regard to total costs or distance (Karimi et al., 2007). Such optimization can be solved with linear programming (LP) by defining the constraints that the cut-and-fill volumes at each location should meet (Son et al., 2005). These techniques have also shown potential in reducing fuel use and the associated emissions (Sanchez et al., 2015). Traditionally, however, these methods do not provide sequencing guidance, meaning that their practical usability may be limited. Nassar and Hosny (2011) extend the allocation problem to a least-cost route cut-and-fill problem, with a solution that specifically determines the route to be travelled in order to fulfill the earthmoving task, thereby providing a work sequence. They propose a solution using a branch-and-bound method and particle swarm optimization (PSO). Moreover, LP-based optimization techniques have been incorporated in commercial planning software for the transport infrastructure construction industry (Shah \& Dawood, 2011). Bogenberger et al. (2015) developed a method for optimizing earthmoving activities by taking into consideration different material types, material recycling, and the impact of using external transportation networks for disposal and borrow pits. $\mathrm{Li}$ and $\mathrm{Lu}$ (2016) developed a method for both optimizing the cut-and-fill matchings and assigning the work with a work-breakdown structure (WBS). Despite the significant contribution of these studies, they can still only be seen as part of wider efforts to minimize or mitigate the effects of earthmoving processes. Another potential way to reduce the impact of earthmoving processes is to consider the machinery used.

\subsection{Earthmoving equipment allocation methods}

Other researchers have focused their analytical efforts on investigating the opportunity to reduce earthmoving impacts by managing the equipment used. This is hardly surprising given that the extensive use of heavy-duty diesel equipment is considered a main element of earthmoving operations. In turn, this means that such equipment is the main contributor to GHG emissions in transport infrastructure projects (Kim et al., 2011, 2012), not to mention its considerable cost impact. Thus, the allocation of equipment and configurations of equipment for earthmoving tasks is another approach highlighted in the literature. Discrete event simulation (DES) is capable of capturing the variability and the complex dynamic interactions between equipment and the earthmoving environment, and it is therefore suitable for determining equipment performance in greater detail (B. Kim \& Y. Kim, 2016). Intelligent approaches for optimization are becoming increasingly used for a wide array of applications across several fields (Nabaei et al., 2018). For instance, Parente et al. (2015) developed an evolutionary multi-objective approach to optimize costs and task duration for different equipment configurations conducting cut-and-fill tasks. Marzouk and Moselhi (2004) implemented a DES-based method to quantify the costs and task duration of equip- 
ment configurations. The method further demonstrated the use of Pareto optimality to address the tradeoff between the target objectives. Moselhi and Alshibani (2009) developed an optimization method using a genetic algorithm, LP, and geographical information systems (GIS) to optimize the equipment usage in an earthworks task. Also relating to earthmoving equipment, a number of studies have recently focused on assessment of the environmental impact of different construction vehicles with or without cost consideration. They have also shown the factors that have an influence on these impacts based on an assumption of standard operating levels for equipment while considering their actual specific level of activities (Abolhasani et al., 2008; Frey et al., 2010; Jassim et al., 2019; Lewis et al., 2011; Kaboli \& Carmichael, 2014; Siami-Irdemoosa \& Dindarloo, 2015). Although these studies are undoubtedly important, they should mainly be seen as complementary to earthmoving planning that should be preceded by identifying the mass quantities and destinations.

A number of the above-mentioned modern techniques and approaches provide promising insights into ways of reducing the costs and task duration impacts related to the allocation of earth and allocation of earthmoving equipment respectively; however, the two approaches to considering environmental effects do not show the maxi- mum potential of reducing total impacts of earthmoving processes by including the capabilities of both approaches in the planning phase. This is because there is no systemic model that integrates all of their useful characteristics in a framework to optimize earthmoving operations (Parente et al., 2016). Consequently, there is a necessity to provide a comprehensive method that can integrate the contributions of both planning approaches within current trends (i.e., environmental goals) in the construction sector in order to maximize saving advantages and mitigate the total impacts in project execution.

One particularly competitive approach for allocating equipment configurations is a simple distance rulebased approach. The simplicity of an approach such as this may facilitate practical implementation and improve understanding among planners, construction managers, and contractors. A valuable twofold contribution from this research can be therefore be discerned: first, a proposed model that integrates EMA and EEA methods to reduce total earthmoving impacts, resulting in a practical approach for decision-making support regarding earthmoving operations; second, the production of theoretical insights into automating the evaluation of earthmoving operations with regard to cost, duration, and environmental impacts.

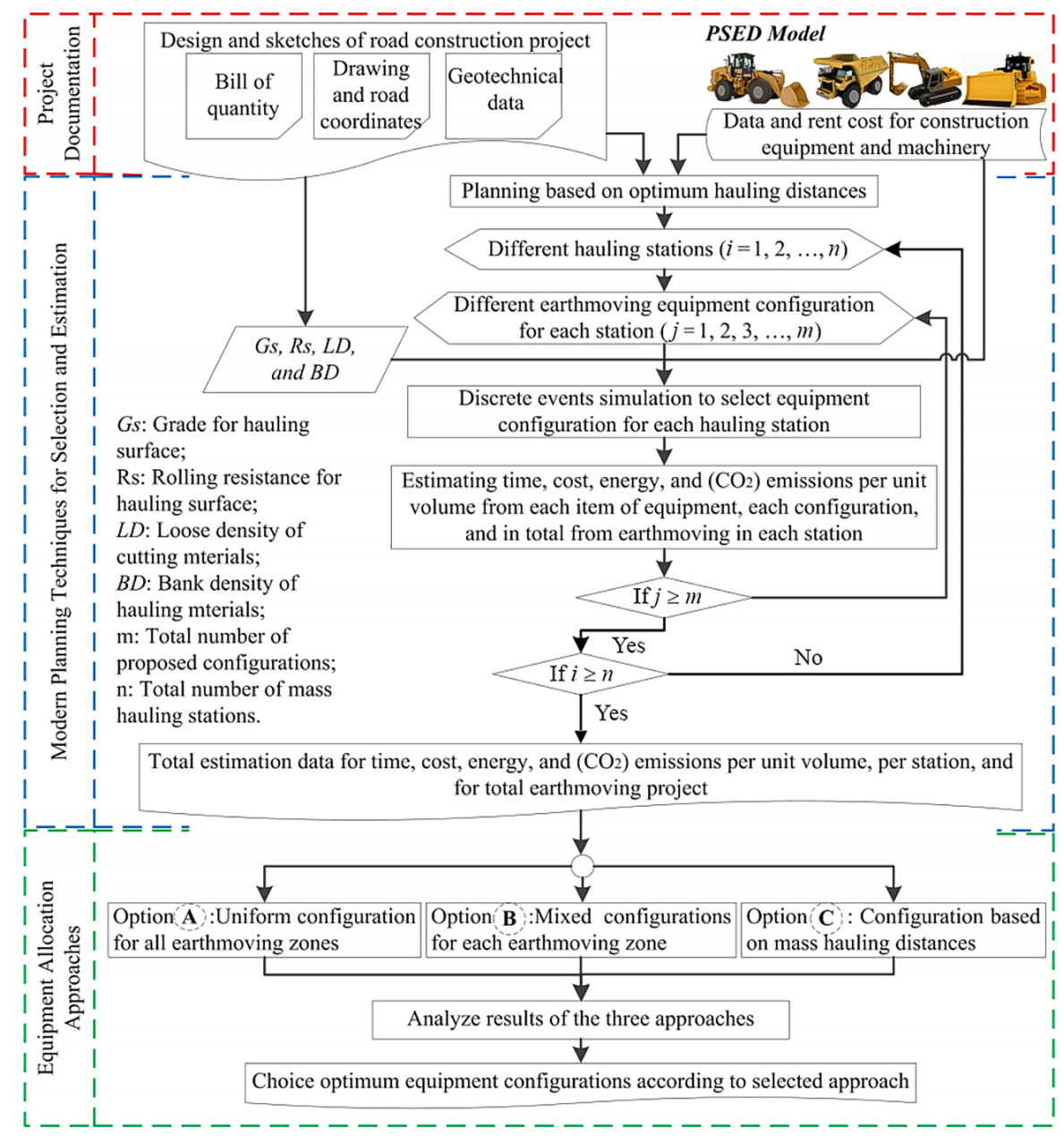

Figure 1. Outline of the Planning, Simulation, Estimation, and Decision-making (PSED) model 


\section{Proposed model}

To meet the aforementioned aims we propose the use of a PSED model, which provides a set of equipment configurations. The PSED model consists of three interconnected successive stages: project documentation, modern planning techniques for selection and estimation, and different approaches to decision-making based on equipment allocation (Figure 1).

\subsection{Project documentation}

In the first stage, the collection and extraction from infrastructure projects of data and information relevant to the planning and execution of earthmoving operations is conducted. These data are mainly classified into two parts; the first part is connected to design details and sketches, and consists of bills of quantities, drawings, and topographical information showing elevations between earthmoving work areas, and material type and density data. The second part comprises performance data for the construction equipment that is available for the contractor-basic operational characteristics, and hire costs. This stage is considered important for planners because it provides knowledge about the entire scale of the project and the conditions and constraints that should be planned for. Therefore, this stage can be considered as a preparation stage that extracts all of the essential data and information to be used as input data for the following stages of planning earthmoving operations.

\subsection{Modern planning techniques for selection and estimation}

In this stage, the hauling distances are optimized and the earthmoving process simulated to produce a plan that can meet two objectives: optimum mass haulage distances and the best equipment configurations based on utilization rates (i.e. work efficiency with limited resources available) against constraints and work conditions (i.e. time, budget, and environmental impact), as well as evaluation of all targets values. Thus, this step is performed by:

1. Mass haul optimization tool (e.g. DynaRoad). This is a program designed to manage earthwork operations in linear construction projects, providing a mass haulage plan based on optimum mass hauling distances between different earthmoving stations in road construction projects. In this study, an earthmoving station is defined by one or two cutting or loading areas that are closely spaced together coupled with one or more dumping areas. However, earthmoving may comprise a number of stations, all of which may be located close together to create a large area called an earthmoving zone (i.e. each zone includes a number of earthmoving stations). Therefore, the earthmoving plan in infrastructure projects may consist of several zones within which earthmoving takes place. In other words, the main output of this step can be described as identifying the optimum distances in a road construction project to haul earthwork materials onsite or offsite.

2. Simulation technique. The best combination of earthmoving equipment to be allocated in a project can be determined using DES to model real work conditions. The choice of equipment configuration in each work station and/or zone is based on duration and cost constraints. Additionally, the utilization rates of each item of equipment in combination are also considered when selecting type, number, and capacity of each piece of equipment within overall configurations. Utilization rates are also used later to determine the weighed percentages of the cost and emissions for each piece of equipment against total cost and emissions of the earthwork operations as a whole. The output from this stage represents the integrated earthmoving plan (i.e. locations and their equipment configurations), which can be described as the optimal hauling distances, with a balance between cost and duration, that provide a high level of equipment utilization rates.

3. Estimation of target values (i.e., time, cost, energy, and $\left(\mathrm{CO}_{2}\right)$ emissions). The time and cost for each configuration to perform earthmoving in each station are computed within the simulation based on cycle time and capacity for each piece of equipment, distances to hauling materials, and hourly rental costs. This stage also entails estimations of energy use and $\mathrm{CO}_{2}$ emissions for all of the equipment configurations that have been nominated to work within each station from the DES. Energy use and $\mathrm{CO}_{2}$ emissions estimates are based on Eqns (1)-(4) developed by Jassim et al. (2018a, 2018b); these are considered the actual productivity rates of earthmoving equipment and load factor values based on the density of hauling materials to estimate energy use and emissions $\left(\mathrm{CO}_{2}\right)$ per unit of volume-based fuel consumption. Equations 1 and 3 are used to estimate energy use $\left(\mathrm{MJ} / \mathrm{m}^{3}\right)$ and $\mathrm{CO}_{2}$ emission $\left(\mathrm{kg} / \mathrm{m}^{3}\right)$ from excavators, wheel-loaders, and bulldozers, while Equations 2 and 4 are used for trucks to consider rolling resistance and grade for hauling surface.

$$
\begin{aligned}
& A n=\left[\frac{S F C \cdot H_{p} \cdot L_{f} \cdot C_{n f}}{\rho_{f u e l} \cdot P_{r a}}\right] ; \\
& T n=\left[\frac{S F C \cdot H_{p t} \cdot C_{n f}}{\rho_{f u e l} \cdot P_{r a}}\right] ; \\
& D m=A n \cdot C_{m f} ; \\
& T m=T n \cdot C_{m f},
\end{aligned}
$$

where $A n$ represents energy used per cubic meter of material hauled by operating the excavator "En", or wheel-loader " $L n$ ", or bulldozer " $B n$ " respectively, at a specific station of the earthmoving operation. Tn is energy used per cubic 
meter of material hauled by operating the trucks. $S F C$ is specific fuel consumption $(0.22 \mathrm{~kg} / \mathrm{kW} . \mathrm{h})$, to be set to a suitable value for engines with power in the range of 28.8 to 370 kW (Hunkeler \& Rebitzer, 2005; Klanfar et al., 2016). $H_{p}$ is the maximum design horsepower of the equipment used $(\mathrm{kW}) . \rho_{\text {fuel }}$ is the specific gravity of the diesel fuel to be consumed $(0.85 \mathrm{~kg} / \mathrm{L})$, ranging between 0.83 and 0.87 $\mathrm{kg} / \mathrm{L} . C_{n f}$ is the conversion factor between fuel and energy, and $C_{m f}$ is the conversion factor between energy and $\mathrm{CO}_{2}$. $P_{r a}$ is the actual productivity rate $\left(\mathrm{m}^{3} / \mathrm{h}\right)$ of the equipment for each level of utilization in the earthmoving operations as simulated in the DES. Dm is emissions $\left(\mathrm{CO}_{2}\right)$ per cubic meter of material hauled by operating the excavator " $\mathrm{Em}$ ", the wheel-loader " $L m$ ", or the bulldozer " $B m$ " respectively, at a specific station of the earthmoving operation; in addition, $\mathrm{Tm}$ represents emissions $\left(\mathrm{CO}_{2}\right)$ per cubic meter of material hauled by operating the trucks. $L_{f}$ is the engine load factor (decimal) for equipment (i.e., excavator, wheelloader, and bulldozer) that was estimated based on bank density and loose density to earth materials using Eqns (5) and (6) developed by Jassim et al. (2017, 2019):

$$
\begin{aligned}
& L_{f}=0.0366 e^{0.00136 B_{D}} ; \\
& \left.L_{f}=0.1707 e\left({ }^{0.0007649 L_{d}}\right)-2.074 e^{-0.004337 L_{d}}\right),
\end{aligned}
$$

where $B_{D}$ represents the materials densities $\left(\mathrm{kg} / \mathrm{m}^{3}\right) . H_{p t}$ is the grade engine horsepower of trucks (see Eqn (7)) accounting for the effect of the total resistance (i.e., grade and rolling resistance), and $G_{s}$ is the hauling road grade (decimal), which is denoted by a positive sign $(+)$ for an up gradient and a negative sign (-) for a down gradient. The surface grade is estimated from longitudinal profiles of the road project by dividing the difference between the average elevations between cutting/loading area and filling/dumping area with the hauling distance.

$$
H_{p t}=\left[\frac{G_{w t} \cdot\left(G_{s}+R_{s}\right) \cdot S_{a v}}{c c} \cdot C_{h p}\right],
$$

where $R_{s}$ is the rolling resistance of the hauling surface that is selected based on the surface type of the haulage route (decimal), $S_{a v}$ is the average hauling speed of the truck $(\mathrm{km} / \mathrm{h}), c c$ represents a constant value (273.75), and $C_{h p}$ represents the conversion factor (0.7457) for converting the energy from HP to $\mathrm{kW} . G_{w t}$ is the total weight of a truck that consists of chassis weight $(\mathrm{kg})$, body weight $(\mathrm{kg})$, and total payload of a truck $(\mathrm{kg})$ based on the loose density of the materials being hauled $\left(\mathrm{kg} / \mathrm{m}^{3}\right)$, and the truck's heaped capacity $\left(\mathrm{m}^{3}\right)$.

The amount of energy used $\left(E n_{\text {conf }}, \mathrm{MJ}\right)$ and $\mathrm{CO}_{2}$ emitted $\left(E m_{\text {conf }}, \mathrm{kg}\right)($ Eqns (8) and (9)) is estimated by the equipment configurations in each station where the contributions from the different equipment used are summarized (e.g. energy use and $\mathrm{CO}_{2}$ emissions of excavator, wheel-loader, bulldozer, and trucks). In addition, the energy consumed $\left(E n_{\text {total }}, \mathrm{MJ}\right)$ and $\mathrm{CO}_{2}$ emissions $\left(E m_{\text {total }}\right.$, $\mathrm{kg}$ ) from all earthmoving zones can be computed by using Eqns (10) and (11).

$$
E n_{\text {conf }}=\left[\sum_{i=1}^{n}(E n)_{i}+\sum_{i=1}^{n}(L n)_{i}+\sum_{i=1}^{n}(B n)_{i}+\sum_{i=1}^{n}(T n)_{i}\right] \cdot V
$$

$E m_{\text {conf }}=\left[\sum_{i=1}^{n}(E m)_{i}+\sum_{i=1}^{n}(L m)_{i}+\sum_{i=1}^{n}(B m)_{i}+\sum_{i=1}^{n}(T m)_{i}\right] \cdot V ;$

$E n_{\text {total }}=\sum_{j=1}^{m}\left(E n_{\text {conf }}\right)_{j}$

$E m_{\text {total }}=\sum_{j=1}^{m}\left(E m_{\text {conf }}\right)_{j}$,

where $E n_{\text {conf }}$ is energy used by equipment configuration in each station of the earthmoving operation, and $E n, L n, B n$, and $T n$ are energy used by operating the excavator, wheelloader, bulldozer, and trucks respectively, in a specific station of the earthmoving operation (where $i=1,2,3, \ldots$, $n$; $n=$ total number of each type of equipment in configuration at each earthmoving station in a road project). $E m_{\text {conf }}$ is $\left(\mathrm{CO}_{2}\right)$ emitted from the equipment configuration in each station of the earthmoving operation, and $\mathrm{Em}, \mathrm{Lm}$, $\mathrm{Bm}$, and $\mathrm{Tm}$ are $\left(\mathrm{CO}_{2}\right)$ emitted from operating the excavator, wheel-loader, bulldozer, and trucks respectively, in a specific station of the earthmoving operation (where $i=$ $1,2,3, \ldots, n ; n=$ total number of each type of equipment in configuration at each earthmoving station in a road project). $V$ is the volume of materials in each mass hauling station of the earthmoving operations. $E n_{\text {total }}$ is the amount of energy used by all equipment configurations in the earthmoving operations, and $E m_{\text {total }}$ is $\left(\mathrm{CO}_{2}\right)$ emitted from all equipment configurations in the earthmoving operations, where $j=1,2,3, \ldots, m ; m=$ total number of earthmoving stations in a road construction project. After estimating the energy use and $\mathrm{CO}_{2}$ emissions of different earthmoving units, the final total data for all earthmoving configurations are calculated. A three-dimensional matrix is thereby produced consisting of time, cost, and environmental impacts (energy use and $\mathrm{CO}_{2}$ emissions). These are the three target objectives that all earthmoving equipment configurations in each workstation are subject to.

\subsection{Equipment allocation approaches}

In the final stage of PSED the best equipment configurations on the basis of the three aforementioned target objectives are selected through analyzing the results of the earthmoving operations for each station. The equipment configurations are allocated according to the following approaches:

- Uniform configuration (A): One configuration allocated for the whole earthmoving process.

- Mixed configurations (B): One configuration allocated per earthmoving station, resulting in mixed configurations throughout the project site. 
- Hauling distance configuration (C): Configuration allocated according to hauling distance range per earthmoving station.

Approach $\mathrm{A}$ is a suitable selection when equipment allocation needs to be kept simple. Approach B enables more detailed planning of equipment allocation as the process is divided per earthmoving section. A simple planning method that enables different equipment configurations to be selected for different zones is to consider hauling distances as the selection criteria, as was done in approach C.

\section{Model application in case study}

A case study was conducted to demonstrate the efficiency of the PSED model in producing optimum earthmoving planning with equipment configurations that can manage the tradeoffs between time, cost, and environmental impacts. Models with similar applications have been demonstrated in other case environments (Carmichael et al., 2014; B. Kim \& Y. Kim, 2016). Figure 2 shows an overview of our case project, which consists of three earthmoving zones selected from a $17 \mathrm{~km}$ road project in southern Sweden, containing a cut volume of about $151992 \mathrm{~m}^{3}$. The project is being undertaken by NCC, a large Swedish construction company. The bidding cost of each unit volume of earthmoving is 55 Swedish krona (SEK) $/ \mathrm{m}^{3}$, which includes all tasks required to execute the earthmoving tasks (e.g. cutting, transporting, filling, distributing, and leveling to the required level for each layer). Three zones (zones D, E and I) were selected from the project, containing cut volumes of approximately $48175 \mathrm{~m}^{3}, 32459 \mathrm{~m}^{3}$ and $71358 \mathrm{~m}^{3}$, respectively. The earth material density and surface type and grade are shown in Subsection 3.1. Further, a more detailed account of the cut quantities and the associated hauling distances for each earthmoving station in the three zones can be seen in Table 5b. In addition, the assumption made is that, during the earthmoving opera- tions, there is no wide variety in weather conditions. The case was selected due to its extensive earthmoving operations and its detailed documentation of equipment, which facilitated our analysis. The structure of the case study is outlined in Figure 3.

\subsection{Input data}

The first step of implementing the PSED model is to gather and organize the necessary input data, which were mainly gathered from the project, and include the bill of quantities for the earthmoving operations, a drawing for the main line of the road construction (i.e. a longitudinal profile), geotechnical data and topography, and data of the earthmoving equipment available (see Table 1). The average bank density of materials excavated is 1886,1835 , and $1943 \mathrm{~kg} / \mathrm{m}^{3}$ for zones D, E, and I respectively. A surface grade of $2 \%$ for hauling operations is estimated in zones $\mathrm{E}$ and I, and 3\% for hauling operations in zone $\mathrm{D}$. The rolling resistance is estimated at 3\% based on the type of haulage surface.

\subsection{Planning}

\subsubsection{Mass haul optimization}

In the first planning step of the PSED model implementation, the hauling distances between cuts and fills are optimized. A bill of quantities in an Excel format, which specifies the cut and fill quantities and locations along the road line, is imported into the DynaRoad platform. Additional locations of borrow pits and disposal areas necessary to compensate for a lack of filling materials, or to dispose of surplus or non-useful materials, are specified manually. DynaRoad summarizes material quantities along the road line into intervals of 50 meters, with some exceptions due to the distribution of different material types. We define such an interval as an earthmoving station, and DynaRoad calculates hauling distances from the center of such stations.

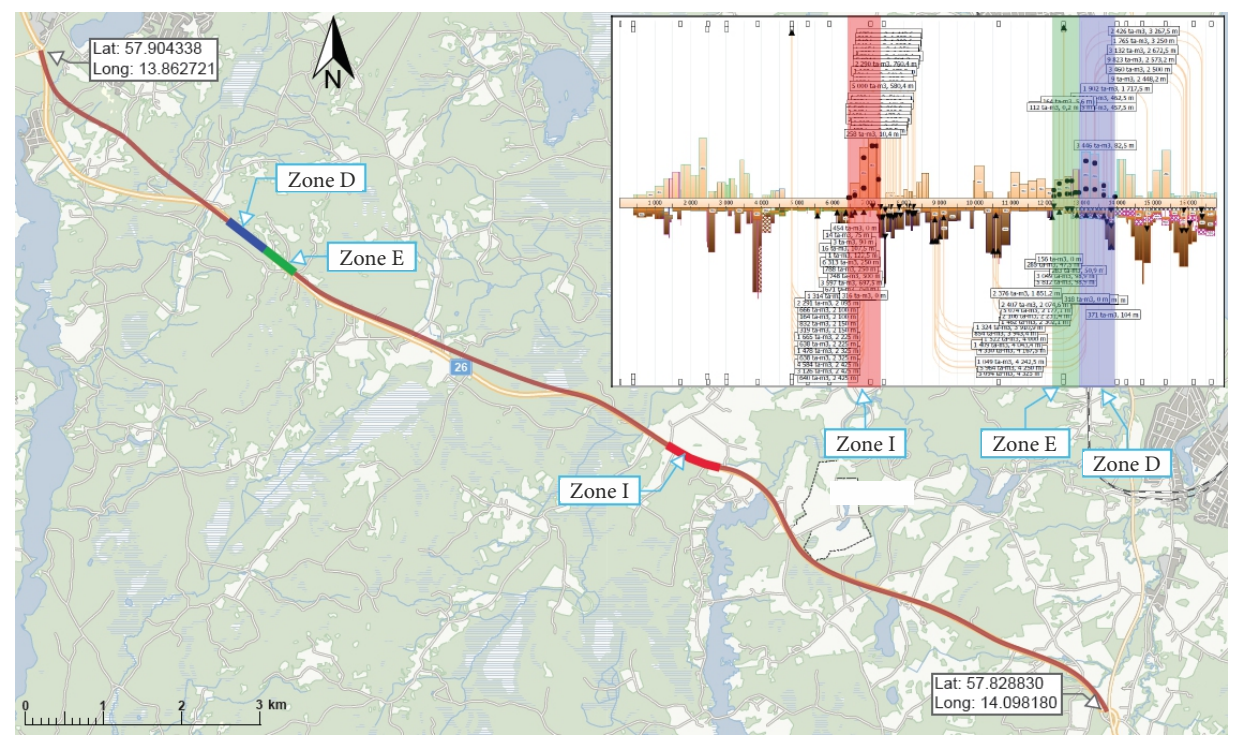

Figure 2. Project map containing earthmoving zones and coordinates 


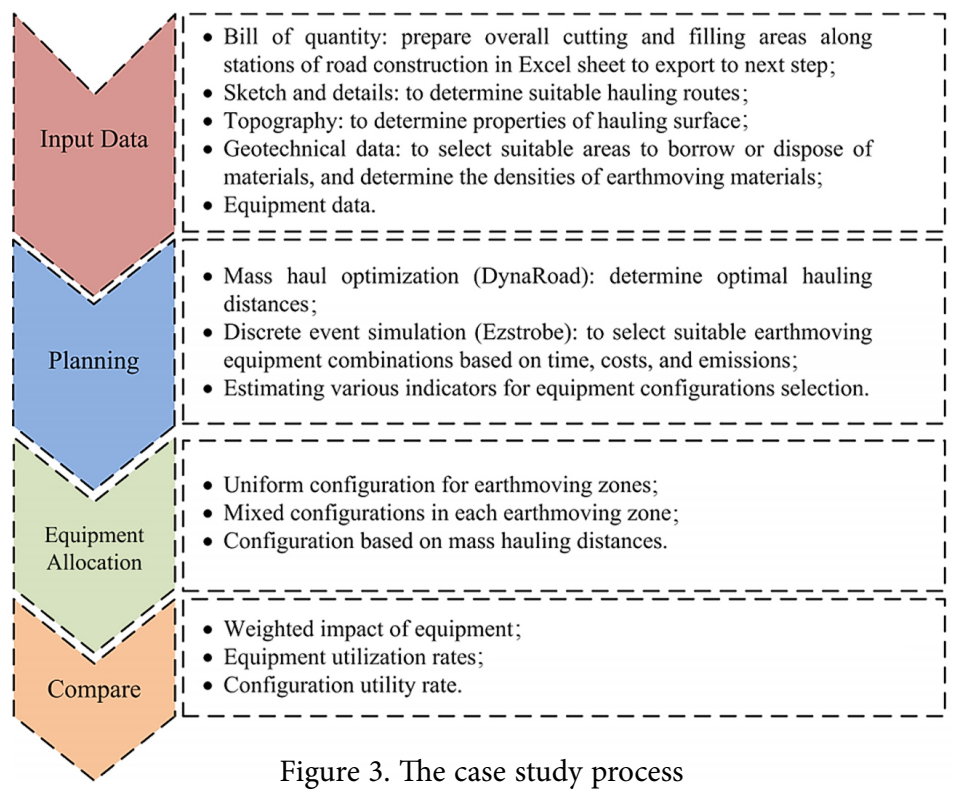

Figure 3. The case study process

Table 1. Equipment available for the selected project

\begin{tabular}{|l|l|c|c|c|c|}
\hline Type of equipment & Model & $\begin{array}{c}\text { Number } \\
\text { of units }\end{array}$ & $\begin{array}{c}\text { Heaped capacity of unit } \\
\left(\mathrm{m}^{3}\right)\end{array}$ & $\begin{array}{c}\text { Engine horsepower } \\
(\mathrm{kW})\end{array}$ & $\begin{array}{c}\text { Hourly rental cost } \\
(\text { SEK) }\end{array}$ \\
\hline Articulated truck & Cat. 725 & 5 & 14.3 & 230 & 800 \\
\hline Off-highway truck & Cat. 770 & 5 & 25.0 & 381 & 900 \\
\hline Off-highway truck & Cat. 772 & 5 & 30.0 & 446 & 94 \\
\hline Excavator & 319DL & 2 & 0.802 & 1000 \\
\hline Excavator & 329D & 2 & 1.101 & 55 & 700 \\
\hline Wheel-loader & $924 \mathrm{~Hz}$ & 1 & 2.1 & 113 & 900 \\
\hline Wheel-loader & $930 \mathrm{H}$ & 1 & 2.5 & 179 & 1000 \\
\hline Bulldozer & D7R & 1 & - & 447 & 1000 \\
\hline Bulldozer & D10T2 & 1 & - & & 1200 \\
\hline
\end{tabular}

DynaRoad calculates the optimal hauling distances automatically using linear-programming, and a simple visualization of the planned hauls can be generated (see Figure 2). In this step we also combine the earthmoving stations into larger zones according to their material characteristics and quantities where it can be expected that the same equipment configurations can conduct the work in sequence. A step like this is commonly conducted in large earthmoving projects to divide the work into more manageable chunks. Three of the zones, seen in Figure 2, were selected to demonstrate the model in this case study.

\subsubsection{Discrete event simulation}

The next planning step of the PSED model focuses on selecting suitable equipment configurations for each earthmoving station based on the optimum mass haul plan that was produced in the preceding step. Ezstrobe, a DES tool to represent earthmoving operations, was used to propose the best equipment configurations for each earthmoving station. The simulation implemented the following constraints:
- Equipment: the items of equipment used cannot exceed in number the items of equipment available.

- Duration: the working hours cannot exceed the total time allocated to earthmoving operations.

- Operating cost: the equipment operating costs cannot exceed the budget allocated to earthmoving operations.

- Utilization rates: utilization rates should be in harmony with realistic equipment utilization in earthmoving operations, or with the improved utilization rate based on rational applicable ideas.

Typically, a simulation template for each earthmoving scenario consists of a number of components and elements that mimic real-world earthmoving operations in road projects (see Figure 4). In addition, the description and distribution function for each item in the template are shown in Table 2.

Based on the equipment and machinery available and drawing on planners' experiences, a number of configurations are proposed for the earthmoving activities project. Table 3 shows six suitable configurations that are pro- 
Table 2. Main items of the DES template

\begin{tabular}{|l|l|l|l|}
\hline Symbol & \multicolumn{1}{|c|}{ Name } & \multicolumn{1}{|c|}{ Description } & \multicolumn{1}{c|}{ Relation/Function } \\
\hline & Queue & $\begin{array}{l}\text { This is a place for waiting until the start of an activity (buffer) re- } \\
\text { quiring these resources. Queves might involve generic or charac- } \\
\text { terized resources (e.g. trucks, excavators, bulldozers, and spotters), } \\
\text { which are logically ordered depending on their function. }\end{array}$ & $\begin{array}{l}\text { Logical relation with boundary } \\
\text { conditions. }\end{array}$ \\
\hline & $\begin{array}{l}\text { Combination } \\
\text { Activity }\end{array}$ & $\begin{array}{l}\text { This describes a specific type of activity to be performed over a } \\
\text { known (distribution probabilistic) duration, from start to end. The } \\
\text { activity always requires a specific combination of resources, and is } \\
\text { fed from the preceding queue(s). }\end{array}$ & $\begin{array}{l}\text { Triangular distribution function } \\
\text { for excavator activities; Uniform } \\
\text { distribution for wheel-loader and } \\
\text { bulldozer/truck activities. }\end{array}$ \\
\hline & $\begin{array}{l}\text { Normal } \\
\text { Activity }\end{array}$ & $\begin{array}{l}\text { This describes a specific type of activity to be performed over a } \\
\text { known (distribution probabilistic) duration, from start to end, for } \\
\text { a single resource. }\end{array}$ & $\begin{array}{l}\text { Pert distribution function for } \\
\text { truck activities (i.e. hauling and } \\
\text { returning). }\end{array}$ \\
\hline & Link & $\begin{array}{l}\text { This shows the flow of logic. For example, links indicate the se- } \\
\text { quence of activities. Activities with occurrence depending on other } \\
\text { activities are also shown. }\end{array}$ & $\begin{array}{l}\text { Logical relation with boundary } \\
\text { conditions. }\end{array}$ \\
\hline
\end{tabular}

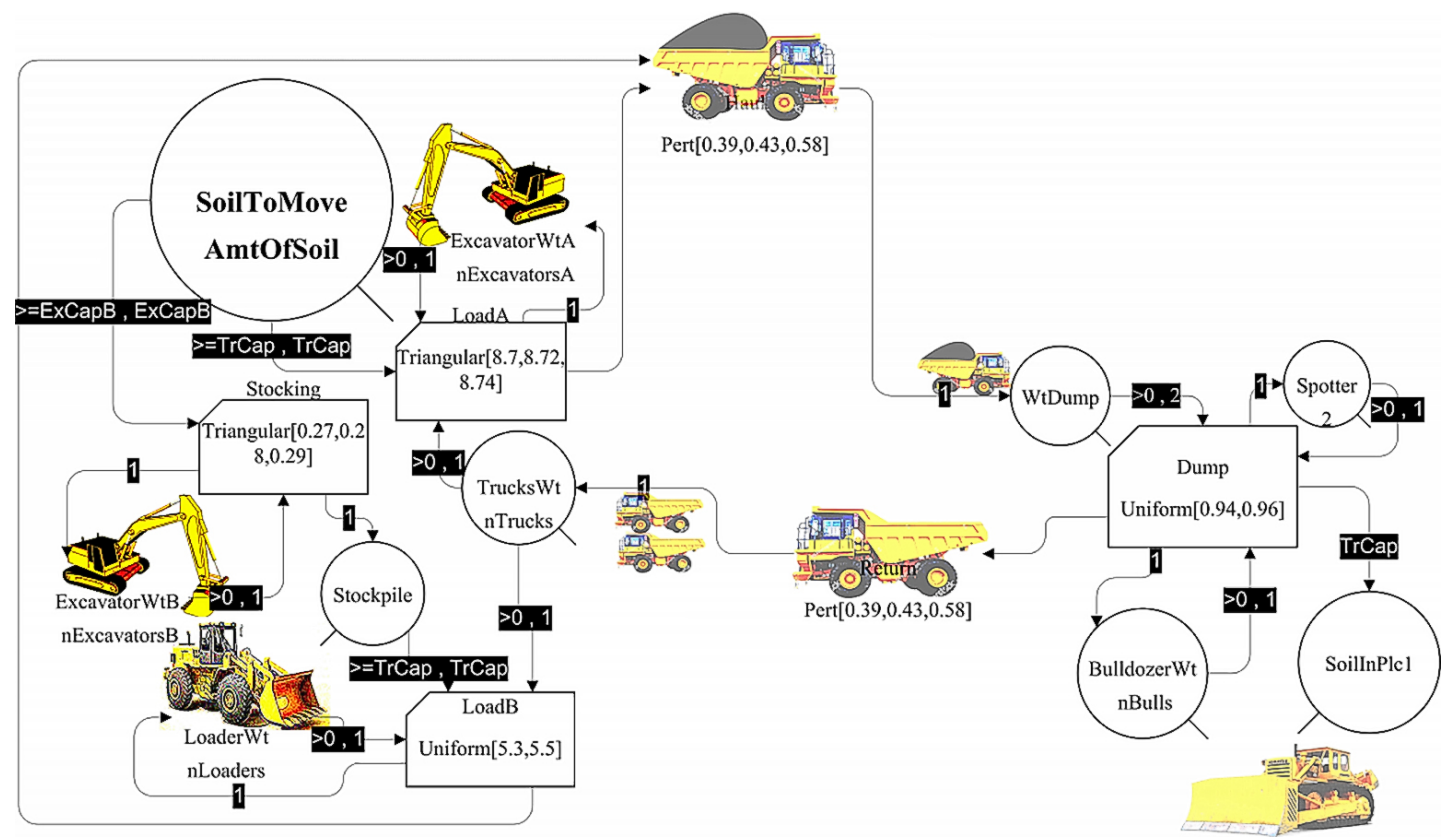

Figure 4. Example of earthmoving simulation template used

Table 3. Suggested equipment configurations

\begin{tabular}{|c|c|c|c|c|}
\hline Configuration No. & No. of trucks & No. of excavators & No. of wheel-loaders & No. of bulldozers \\
\hline I & 5 (Cat. 770) & $2(319 \mathrm{DL})$ & $1(924 \mathrm{~Hz})$ & $1(\mathrm{D} 10 \mathrm{~T} 2)$ \\
\hline II & 3 (Cat. 772) & 2 (319DL and 329D) & $1(930 \mathrm{H})$ & $1(\mathrm{D} 7 \mathrm{R})$ \\
\hline III & 5 (Cat. 772) & $2(329 \mathrm{D})$ & $1(924 \mathrm{~Hz})$ & $1(\mathrm{D} 10 \mathrm{~T} 2)$ \\
\hline IV & 5 (Cat. 770) & $2(319 \mathrm{DL})$ & $1(924 \mathrm{~Hz})$ & $1(\mathrm{D} 7 \mathrm{R})$ \\
\hline V & 3 (Cat. 725) & $1(319 \mathrm{DL})$ & - & $1(\mathrm{D} 7 \mathrm{R})$ \\
\hline VI & 5 (Cat. 725) & $1(319 \mathrm{DL})$ & - & $1(\mathrm{D} 7 \mathrm{R})$ \\
\hline
\end{tabular}

posed to test overall earthmoving zones in terms of offering higher productivity rates within earthmoving operations and the lowest cost within time constraints across all zones. The configurations V and VI are used in earthmoving operations in real road projects (identified from project documents).

\subsubsection{Estimation and computation} of time, cost, energy, and emissions

The cost and time required for each hauling operation were computed within the DES model; in the case of cost estimating, the model considers a total hourly hire cost for each configuration at each station that is based on the 
hourly hire cost for each item of equipment involved in earthmoving, then divided by the actual level of productivity for the specific configuration in workstations of each scenario, in order to calculate cost per unit of the hauled materials; in other words, varied values at each station were mainly dependent on the type of equipment combination used and the hauling distances between loading and dumping areas. Meanwhile, time is computed from each scenario based on a cycle time interval (minimum and maximum values) with a suitable kind of distribution that can mimic real-world behavior of each piece of equipment used in each configuration at each station, plus waiting times for each item of equipment in different areas through the scenario. In addition, the time taken to haul materials from the loading area to the dumping area was computed by dividing the hauling distance from each scenario by the assumed speed interval within specific distribution to produce a hauling time and then summed with dumping time. Equations (1)-(7) described above in Section 2 are used to estimate energy use and $\mathrm{CO}_{2}$ emissions per cubic meter of earthmoving for all equipment and machinery used. The energy consumption and $\mathrm{CO}_{2}$ emissions are computed for each station by Eqns (8) and (9), and over all earthmoving zones in the road project by Eqns (10) and (11). At the end of this step, the values of time, cost, energy, and emissions $\left(\mathrm{CO}_{2}\right)$ for all mass hauling in each zone are computed. The results are then exported to MATLAB platform in the form of data matrices in order to start the last stage of the PSED model that focuses on providing an optimum alternative of equipment configurations to reduce earthmoving impacts. The earthmoving zones selected involved a large number of cutting and filling activities within various hauling distances to cover all variations in earthmoving conditions and requirements over the entire road project.

\subsection{Equipment allocation}

The results of the preceding stages are analyzed with approaches $\mathrm{A}, \mathrm{B}$, and $\mathrm{C}$, with the goal of allocating equipment configurations to the earthmoving project according to the defined objectives. The results of each approach are presented in the following sections.

\subsubsection{Approach A: Uniform configuration for all earthmoving zones}

The first approach entails allocating one equipment configuration to the whole earthmoving process; the results of the values for time, cost, energy, and emissions $\left(\mathrm{CO}_{2}\right)$ from using different equipment configurations in three earthmoving zones are shown in Table 4. These results were computed from the simulation outputs for each configuration for conducting all earthmoving operations within each station in the three zones. The total results from the earthmoving zones (D, E, and I) show that configuration III has the lowest execution time, costs, energy use, and $\mathrm{CO}_{2}$ emissions. The individual results obtained from zones $\mathrm{D}$ and $\mathrm{E}$ show the same indicators for configu- ration selection that appeared in all earthmoving zones, whereas in zone I (although configuration III has the lowest execution time) there are slightly higher costs, energy use, and $\mathrm{CO}_{2}$ emissions than for configuration II. This difference is due to the difference in engine size for the equipment used in each configuration, which affects the amount of energy used and emissions (for example, the different ratios of sensitivity to increased emissions from the equipment against the change in the gradient of the haulage surface and increase density of materials excavated/hauled that basically effects on engine load). The result shows that configuration III in the studied zones had the lowest time, cost, energy use, and $\mathrm{CO}_{2}$ emissions. It is therefore considered to be the first option (A) suggested when planning earthmoving operations according to approach A.

\subsubsection{Approach B: Mixed configurations per earthmoving zone}

The second approach selects configurations based on each studied station and on the total impacts of earthmoving zones, thus providing a mixed configuration in every earthmoving zone. This mix is achieved through a multiobjective particle swarm optimization (MOPSO) method in order to find all possible tradeoffs between the conflicting objectives (Goh et al., 2010). Using MOPSO reveals tradeoffs between time, cost, and environmental impact within defined constraints and conditions, thereby finding optimal selection solution(s) in terms of equipment configurations, together with their related impacts. The optimum results are known as non-dominated solutions because in such cases there are no other solutions superior in all features that can represent a set of non-dominated solutions lying along a surface called the "Pareto front" (Horn et al., 1994). The Pareto concept is also commonly termed the Pareto optimal set, or efficient points and admissible points (Fonseca \& Fleming, 1993). Deb (2001) showed that Pareto solutions are non-dominated with output matrices, but they are better than other non-Pareto options in multi-objective problems. However, tradeoffs among conflicting objectives through moving between $\mathrm{Pa}$ reto solutions always lead to a sacrifice in one objective to achieve a gain in (an)other (Konak et al., 2006). According to Lavin (2015) there are two general methods that produce multi-objectives optimization: (i) a single, composite function that combines the individual objectives, and (ii) determining a Pareto optimal solution set, which is the approach adopted in this study. The discrete variables in the input matrices represent various equipment configurations in respect of our target values from each configuration, with a maximum value against earthmoving quantities in every station.

In this algorithm, an initial swarm that includes a number of particles is created at the outset. Each particle represents one solution of the problem that has moves along a trajectory based on the relation between its last position and current best position. In addition, during 
Table 4. Results by earthmoving zones and in total possible impact reduction comparison with configuration III

\begin{tabular}{|c|c|c|c|c|c|c|c|c|c|}
\hline \multirow{2}{*}{ Zone } & \multirow{2}{*}{$\begin{array}{c}\text { Configuration } \\
\text { No. }\end{array}$} & \multicolumn{2}{|c|}{ Time } & \multicolumn{2}{|c|}{ Cost } & \multicolumn{2}{|c|}{ Energy use } & \multicolumn{2}{|c|}{$\mathrm{CO}_{2}$ emissions } \\
\hline & & hour $/ \mathrm{m}^{3}$ & hours & $\mathrm{SEK} / \mathrm{m}^{3}$ & $(1000 *$ SEK $)$ & $\mathrm{MJ} / \mathrm{m}^{3}$ & $\left(1000^{\star} \mathrm{MJ}\right)$ & $\mathrm{kg} / \mathrm{m}^{3}$ & $\left(1000^{\star} \mathrm{kg}\right)$ \\
\hline \multirow{6}{*}{$\mathrm{D}$} & I & 0.0037 & 183.3 & 27.81 & 1539.8 & 66.36 & 3334.3 & 4.83 & 242.8 \\
\hline & II & 0.0044 & 212.3 & 28.03 & 1486.1 & 75.37 & 3770.0 & 5.51 & 275.2 \\
\hline & III & 0.0026 & 127.9 & 26.46 & 1215.3 & 65.17 & 3240.5 & 4.72 & 233.9 \\
\hline & IV & 0.0037 & 183.5 & 27.16 & 1504.6 & 59.69 & 2991.9 & 4.36 & 218.6 \\
\hline & $\mathrm{V}$ & 0.0082 & 413.2 & 36.34 & 1818.3 & 75.73 & 3775.9 & 5.39 & 268.9 \\
\hline & VI & 0.0061 & 298.6 & 36.92 & 1791.5 & 78.37 & 3841.9 & 5.62 & 274.1 \\
\hline \multirow{6}{*}{$\mathrm{E}$} & I & 0.0032 & 101.2 & 24.01 & 849.8 & 50.84 & 1642.5 & 3.71 & 118.7 \\
\hline & II & 0.0036 & 110.6 & 22.94 & 773.9 & 54.05 & 1642.9 & 3.93 & 118.6 \\
\hline & III & 0.0022 & 67.8 & 21.74 & 644.5 & 48.56 & 1555.7 & 3.50 & 111.0 \\
\hline & IV & 0.0032 & 101.1 & 23.41 & 828.9 & 52.08 & 1681.7 & 3.80 & 121.6 \\
\hline & V & 0.0065 & 208.4 & 28.91 & 916.9 & 53.90 & 1702.0 & 3.86 & 120.5 \\
\hline & VI & 0.0059 & 191.3 & 35.75 & 1147.6 & 63.21 & 1993.4 & 4.61 & 144.8 \\
\hline \multirow{6}{*}{ I } & I & 0.0031 & 210.2 & 23.37 & 1765.5 & 49.34 & 3467.9 & 3.57 & 250.1 \\
\hline & II & 0.0028 & 191.0 & 17.91 & 1337.1 & 43.192 & 2946.5 & 3.11 & 211.4 \\
\hline & III & 0.0021 & 138.3 & 21.36 & 1313.9 & 46.99 & 3209.6 & 3.39 & 229.3 \\
\hline & IV & 0.0031 & 210.2 & 22.83 & 1723.7 & 50.54 & 3667.9 & 3.66 & 265.0 \\
\hline & $\mathrm{V}$ & 0.0059 & 416.7 & 26.15 & 1833.7 & 46.30 & 3262.7 & 3.32 & 233.3 \\
\hline & VI & 0.0059 & 416.9 & 35.68 & 2501.8 & 53.73 & 3796.6 & 3.88 & 273.6 \\
\hline \multirow{6}{*}{ Total } & I & 0.0033 & 494.7 & 24.76 & 4155.1 & 54.44 & 8444.6 & 3.95 & 611.6 \\
\hline & II & 0.0034 & 513.9 & 21.90 & 3597.2 & 54.69 & 8359.4 & 3.97 & 605.3 \\
\hline & III & 0.0023 & 334.1 & 22.87 & 3173.7 & 52.43 & 8005.7 & 3.79 & 574.3 \\
\hline & IV & 0.0033 & 494.8 & 24.17 & 4057.3 & 53.457 & 8341.6 & 3.89 & 605.3 \\
\hline & V & 0.0067 & 1038.4 & 29.64 & 4568.8 & 56.28 & 8740.7 & 4.02 & 622.7 \\
\hline & VI & 0.0059 & 906.8 & 36.04 & 5440.9 & 62.81 & 9631.9 & 4.54 & 692.6 \\
\hline \multirow{5}{*}{$\begin{array}{l}\text { Impacts reduction (\%) } \\
\text { by using configuration III } \\
\text { comparison with other } \\
\text { configurations }\end{array}$} & I & & $32 \%$ & & $24 \%$ & & $5 \%$ & & $6 \%$ \\
\hline & II & & $35 \%$ & & $12 \%$ & & $4 \%$ & & $5 \%$ \\
\hline & IV & & $32 \%$ & & $22 \%$ & & $4 \%$ & & $5 \%$ \\
\hline & $\mathrm{V}$ & & $68 \%$ & & $31 \%$ & & $8 \%$ & & $8 \%$ \\
\hline & VI & & $63 \%$ & & $42 \%$ & & $17 \%$ & & $17 \%$ \\
\hline
\end{tabular}

each iteration the position and velocity for particles are changed to obtain better solutions. The best position of each particle (e.g., in this study, one that minimizes objective function) is called local best (pbest) while the best position of the swarm is called a global best (gbest). Thus, an optimum solution is defined by the particle-updating mechanism within PSO (Kennedy \& Eberhart, 1995). This mechanism is formulated in Eqns (12)-(14).

$$
\begin{aligned}
& V_{i j}^{(t)}=W^{(t-1)} \cdot V_{i j}^{(t-1)}+c_{1} \cdot r_{1}\left(\text { pbest } X_{i j}^{(t-1)}-X_{i j}^{(t-1)}\right)+ \\
& c_{2} \cdot r_{2}\left(\text { gbest } X_{i j}^{(t-1)}-X_{i j}^{(t-1)}\right) ; \\
& X_{i j}^{(t)}=X_{i j}^{(t-1)}+V_{i j}^{(t)} ; \\
& W(t)=W_{\max }-\left(W_{\Delta} \cdot \alpha_{t}\right),
\end{aligned}
$$

where $t=1,2, \ldots, T$ represents the iteration of PSO and $T$ stands for the total iteration limit, $W(t)$ denotes inertia weight computed using equation (14) to improve the ability of PSO based on its nonlinear decreasing value (Tuppadung \& Kurutach, 2011), $W_{\max }$ represents a maximum inertia weight limit (1.2), where the minimum limit is (0.1), and $W_{\Delta}$ represents the difference between the maximum and minimum limit values of inertia weights. $\alpha_{t}$ represents the quotient of dividing the number of current iteration $(t)$ by the total iteration limit $(T) \cdot c_{1}$ and $c_{2}$ are called acceleration coefficients that affect the relationship between local best and global best position for particles, and $r_{1}$ and $r_{2}$ are uniform random numbers between $(0-1) . X_{i j}{ }^{t}$ denotes the position of the $i j^{\text {th }}$ particle in the $t^{\text {th }}$ iteration for the three dimensions earthmoving metrics, whereas pbestx $_{i j}{ }^{t}$ and gbest $x_{i j}{ }^{t}$ represent the local and global best positions of the $X^{\text {th }}$ particle in $(t-1)^{\text {th }}$ iteration, respectively. $V_{i j}{ }^{(t-1)}$ and $X_{i j}{ }^{(t-1)}$, respectively, represent the previous velocity and position that was used for calculating the velocity $\left(V_{i j}{ }^{t}\right)$ and position $\left(X_{i j}{ }^{t}\right)$ of the $k^{\text {th }}$ succeeding particle in the $t^{\text {th }}$ iteration. 
In order to increase the dominance tournaments among the competing outputs of MOPSO, the input data of 50 earthmoving configurations (i.e. random configuration selections from simulations with higher impacts) was included with the existing six configurations selected previously so as to investigate the ability of approach B to reduce total earthmoving impacts. MOPSO was automatically processed for 70 runs (i.e. repetition for PSO running time) to improve the algorithm performance and thereby to increase the accuracy of optimization. Thus, the matrices of earthmoving impacts for the proposed equipment configurations were entered into the MATLAB platform to perform PSO optimization that was employed to manage the tradeoff between traditional targets, and environmental impact over all equipment configurations and throughout all stations within the three zones. Figure 5 presents execution screen of PSO within MATLAB platform.

Although for optimization purposes 50 earthmoving configurations were tested over 43 earthmoving stations throughout the three zones, the useful outputs were only four Pareto options (shown in Table 5a) that were produced in 42.0 seconds. These options represent the number of configurations obtained as optimum solutions within the set of Pareto feasible solutions (i.e., number of points that draw an imagined surface of limited area of optimization). Thus, based on the project considerations and preferences, planners can select from any of these $\mathrm{Pa}$ reto options, which are non-dominated with each other on all entered options (i.e., the metrics of input impacts). In this case, Output (3) is considered by the planner and construction manager as a suitable option since it offers the second-lowest cost and emissions, and third lowest project duration within the four optimum solutions. Therefore, the criterion used to select the configuration-mix within options shown in Table $5 \mathrm{~b}$ that can meet stakeholder aims is that of mitigating the environmental impact of the earthmoving operations with the lowest effect on the execution costs estimated in the previous step. Thus, when compared to approach $\mathrm{A}$, approach $\mathrm{B}$ can reduce the environmental impact (7\% and 6\%, respectively) for energy use and $\mathrm{CO}_{2}$ emissions, with approximately the same cost and only a longer duration $\sim 21 \%$.

\subsubsection{Approach C: Configuration based on mass hauling distances}

A third approach to decision-making in the final stage of the PSED is achieved by analyzing the effects of changing haulage distances for each equipment configuration at each station in each zone against the target parameters in the final earthmoving plan. The results in Figures 6-11 show that equipment configuration II can be considered a more suitable configuration to use in earthmoving operations in the project when hauling earth/materials over distances of less than $1.5 \mathrm{~km}$ (where all other project conditions remain constant). Configuration III is superior for minimizing earthmoving impacts at haulage distances of between $1.5 \mathrm{~km}$ and $5.0 \mathrm{~km}$. The results show an incremental cost and emissions $\left(\mathrm{CO}_{2}\right)$ per each cubic meter of earth moved with increasing haulage distances for different sizes of earthmoving operations in each zone. The non-linear behavior of the increase in the target parameters in Figures 6-11 is due to variations in the operational characteristics for configurations and project conditions for every station.

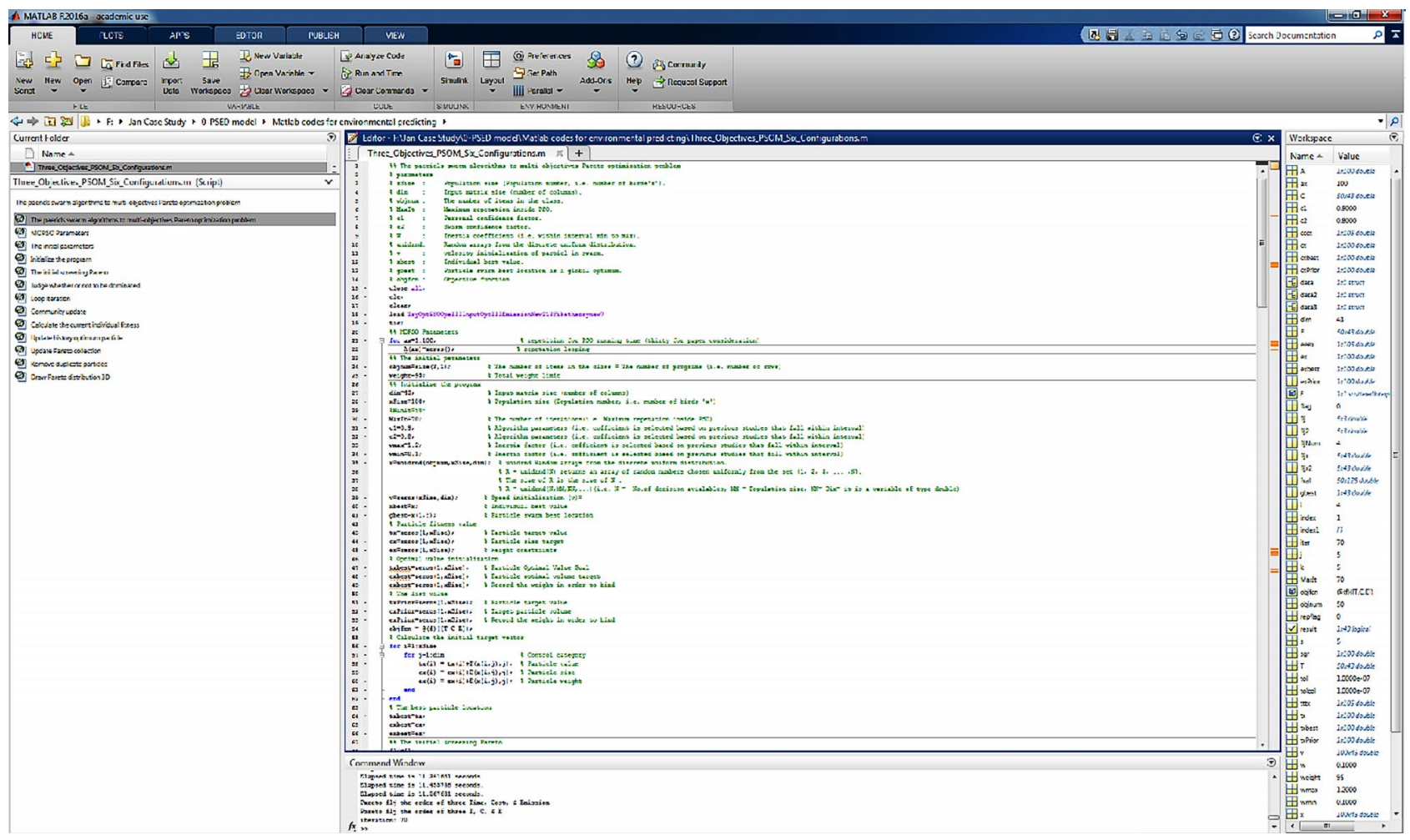

Figure 5. Execution screen of PSO code used to manage conflicting objectives of earthmoving operations 
Table 5a. Total amount of time, cost, and emissions for four optimum outputs within the Pareto feasible solution

\begin{tabular}{|l|c|c|c|}
\hline \multicolumn{1}{|c|}{ Pareto Optimal Output } & Time (hours) & Cost $\left(1000^{\star} \mathrm{SEK}\right)$ & $\mathrm{CO}_{2}\left(1000^{\star} \mathrm{kg}\right)$ \\
\hline Optimal Output 1 & 439.5 & 3265.5 & 560.0 \\
\hline Optimal Output 2 & 406.8 & 3205.9 & 534.7 \\
\hline Optimal Output 3 & $\mathbf{4 1 2 . 9}$ & $\mathbf{3 1 7 7 . 8}$ & $\mathbf{5 3 9 . 6}$ \\
\hline Optimal Output 4 & 408.9 & 3083.6 & 574.9 \\
\hline
\end{tabular}

Table 5b. Configuration selection based on MOPSO by earthmoving station

\begin{tabular}{|c|c|c|c|c|c|c|c|c|c|}
\hline Zone & Station & $\begin{array}{c}\text { Quantity } \\
\left(\mathrm{m}^{3}\right)\end{array}$ & $\begin{array}{c}\text { Hauling } \\
\text { Distance (m) }\end{array}$ & $\begin{array}{c}\text { Configuration } \\
\text { No. }\end{array}$ & Zone & Station & $\begin{array}{c}\text { Quantity } \\
\left(\mathrm{m}^{3}\right)\end{array}$ & $\begin{array}{c}\text { Hauling } \\
\text { Distance (m) }\end{array}$ & $\begin{array}{c}\text { Configuration } \\
\text { No. }\end{array}$ \\
\hline \multirow{12}{*}{$\mathrm{D}$} & \multirow{12}{*}{$12950-13958$} & 2426 & 3267.5 & IV & \multirow{22}{*}{ I } & \multirow{22}{*}{$6435-7325$} & 1815 & 1885 & III \\
\hline & & 1765 & 3250 & IV & & & 1524 & 1393.6 & III \\
\hline & & 405 & 2823.2 & III & & & 1636 & 1250 & III \\
\hline & & 7006 & 2500 & IV & & & 288 & 1154 & II \\
\hline & & 2122 & 1717.5 & IV & & & 2407 & 1005.4 & III \\
\hline & & 8054 & 462.5 & II & & & 5034 & 801.3 & III \\
\hline & & 2548 & 197.5 & $\mathrm{~V}$ & & & 2290 & 760.4 & II \\
\hline & & 1396 & 107.5 & II & & & 1478 & 685.4 & III \\
\hline & & 3901 & 4000 & IV & & & 7582 & 580.4 & II \\
\hline & & 3901 & 4092.5 & IV & & & 1629 & 510.4 & II \\
\hline & & 6086 & 4215 & III & & & 3500 & 440.7 & II \\
\hline & & 8565 & 4325 & IV & & & 7218 & 362.9 & II \\
\hline \multirow{10}{*}{$\mathrm{E}$} & \multirow{10}{*}{$12199-12950$} & 2407 & 2074.6 & III & & & 258 & 130 & II \\
\hline & & 5074 & 2177.1 & III & & & 3402 & 117.9 & II \\
\hline & & 2059 & 2231.4 & IV & & & 7101 & 250 & III \\
\hline & & 2411 & 2302.1 & IV & & & 748 & 500 & II \\
\hline & & 2685 & 4043.4 & III & & & 4268 & 697.5 & II \\
\hline & & 2790 & 125.5 & II & & & 707 & 1302.5 & II \\
\hline & & 7959 & 98.9 & II & & & 145 & 1462.5 & II \\
\hline & & 522 & 1701 & III & & & 17920 & 1575.5 & III \\
\hline & & 952 & 1851.2 & III & & & 408 & 1750 & $\mathrm{~V}$ \\
\hline & & 5600 & 1945 & III & & & & & \\
\hline
\end{tabular}

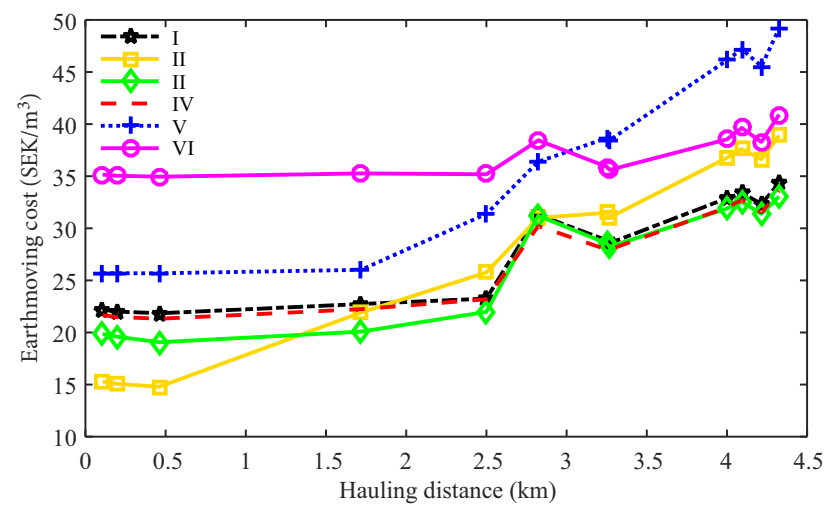

Figure 6. Cost per unit of mass hauling by configuration in zone $\mathrm{D}$

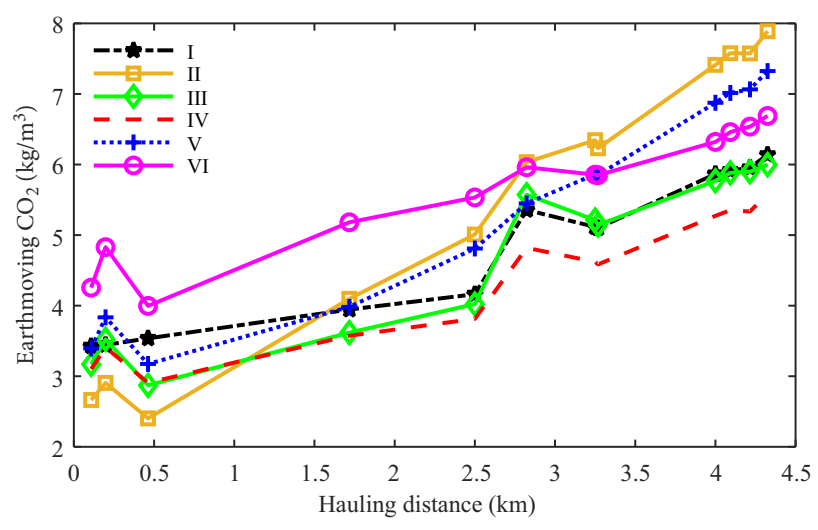

Figure 7. $\mathrm{CO}_{2}$ emissions per unit of mass hauling by configuration in zone $\mathrm{D}$ 


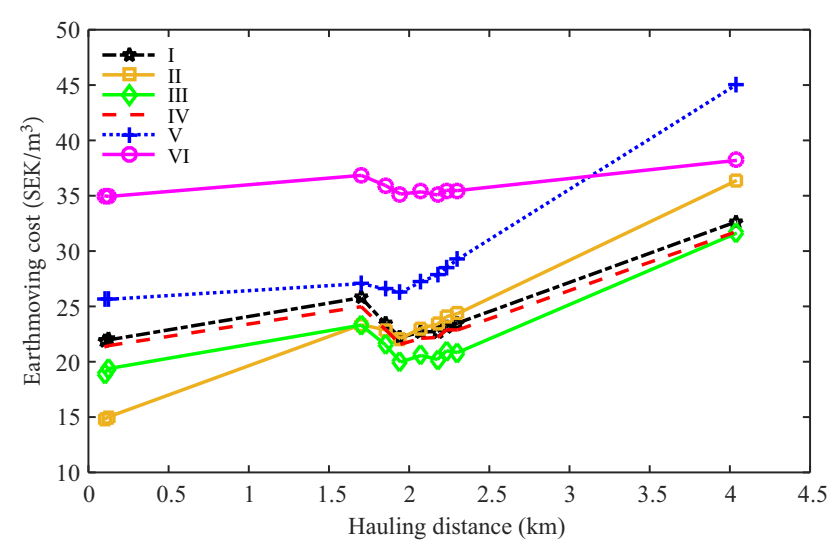

Figure 8. Cost per unit of mass hauling by configuration in zone $\mathrm{E}$

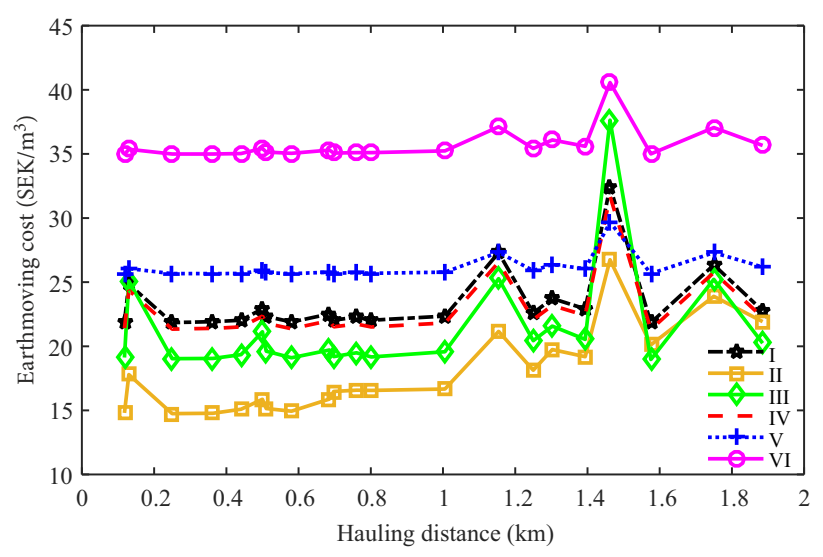

Figure 10. Cost per unit of mass hauling by configuration in zone I

\subsection{Comparisons with other technical terms/concepts}

To ensure that the results of the aforementioned equipment allocation approaches are realistic and in agreement with findings from other researches some additional data are introduced to enable comparisons. The idea was to test the realism of our proposed/adopted approaches visà-vis different indications of earthmoving equipment/ configurations by comparing them to other studies that have used similar elements or terms. Therefore, this study chose three terms frequently used in earthmoving operations management to support decision-making in cases of equipment selection: (i) weighted impact of equipment, (ii) equipment utilization rates, and (iii) utility values of equipment configurations.

\subsubsection{Weighted impact of equipment}

In the context of evaluating the effects of each type of equipment on the total performance of earthmoving projects, this subsection specifically shows the major impacts of the main equipment used in the earthmoving operations. These impacts are figured in terms of cost and emissions $\left(\mathrm{CO}_{2}\right)$ as an indication or benchmark for selecting equipment combinations that are more suitable for oper-

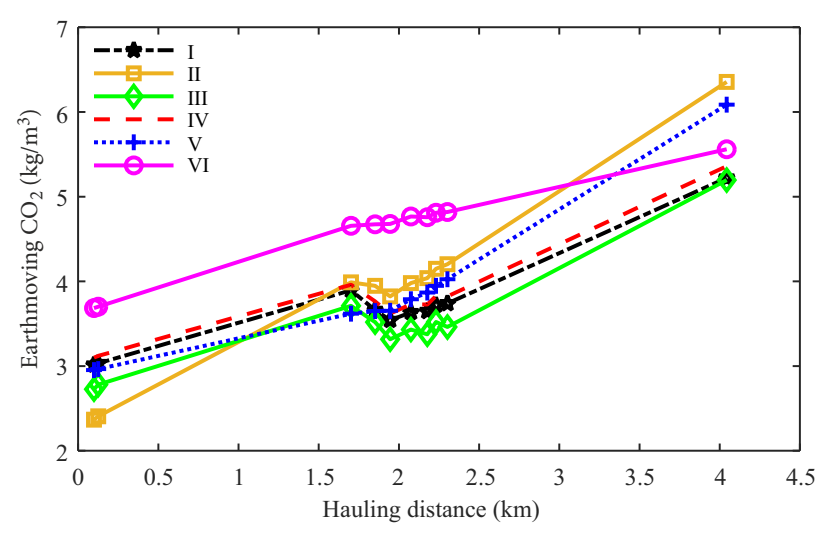

Figure 9. $\mathrm{CO}_{2}$ emissions per unit of mass hauling by configuration in zone $\mathrm{E}$

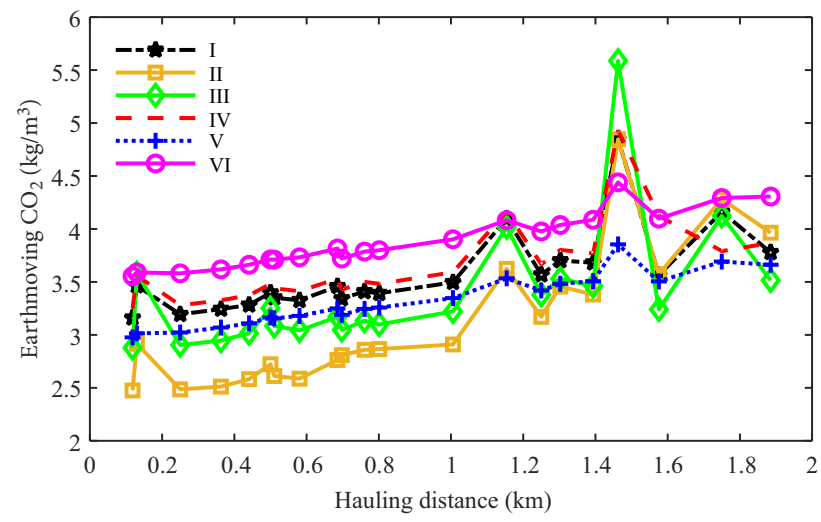

Figure 11. $\mathrm{CO}_{2}$ emissions per unit of mass hauling by configuration in zone I

ating in earthmoving in road and infrastructure projects when compared to other similar types of equipment. There are two particularly significant factors that emerge regarding equipment operations that can be used as indicators to guide planners considering the primary impact of the use of each equipment type in earthmoving projects. These are represented by a cost weighted ratio for each piece of equipment against total cost, and by an emissions weighted ratio for each piece of equipment against total emissions. The weighted ratios for each piece of equipment in the entire earthmoving operation are calculated in the last stage of the PSED model because all values of earthmoving operations needed to calculate these indicators should have been accounted for at the end of stage three of the PSED. Each factor is computed by dividing the sum of the total multiplying cost or emissions for each type of equipment throughout the earthmoving project by the total cost or emissions of the earthmoving equipment. Above all, the fundamental idea of this subsection is to demonstrate the degree of agreement between the final outputs of this study and real-world operations; in other words, the aim is to show its planning strength by mimicking and representing real-world operations that had been measured or estimated by other studies. The weighted ratios of equipment are calculated by using Eqns (15) and (16): 


$$
\begin{gathered}
C_{w r}=\frac{\sum_{i=1}^{n} C_{i} \cdot T_{i}}{\sum_{j=1}^{m} \sum_{i=1}^{n}\left(C_{i} \cdot T_{i}\right)_{j}} ; \\
E_{w r}=\frac{\sum_{k=1}^{l} E_{k} \cdot V_{k}}{\sum_{q=1}^{r} \sum_{k=1}^{l}\left(E_{k} \cdot V_{k}\right)_{r}},
\end{gathered}
$$

where $C_{w r}$ is the cost weighted ratio for the specific type of equipment against total cost of earthmoving operations (decimal) (see Table 6), $C_{i}$ represents the hourly hire cost of a specific item of equipment used in earthmoving operations, $T_{i}$ represents the time of operating a specific item of equipment in each earthmoving station (where $i=1,2$, $3, \ldots, n ; n=$ number of total stations in a road project; and $j=1,2,3, \ldots, m ; m=$ total different types of equipment used in the earthmoving operation), $E_{w r}$ is the energy or emissions weighted ratio for the specific type of equipment against total energy or emissions of the earthmoving operation (decimal) (see Table 6), $E_{k}$ is energy or emissions per cubic meter of matter produced from operating a specific type of equipment in each station $\left(\mathrm{MJ}\right.$ or $\left.\mathrm{kg} / \mathrm{m}^{3}\right)$, and $V_{k}$ is the volume of earthmoving in each station $\left(\mathrm{m}^{3}\right)$ (where $k=1,2,3, \ldots, l ; l=$ number of mass haul stations in earthmoving operations; and $q=1,2,3, \ldots, r ; r=$ total different types of equipment used in the earthmoving operation). Table 6 represents weighted ratios in terms of cost and emissions for each type of equipment used in each configuration throughout the earthmoving zones.

The results show that trucks have a large impact on the total costs and $\mathrm{CO}_{2}$ emissions, ranging from $47 \%-67 \%$ and $55 \%-85 \%$ respectively, across all studied equipment configurations. Configurations using one loading area (i.e., V and VI) or a greater number of trucks (i.e., I, III, IV, and VI) have higher weighted ratios for trucks overall. In addition, the cost weighted ratio for excavator and bulldozer was the same in configurations V and VI due to each piece of equipment having one unit being operated in the configuration but with the same hourly rental costs and total operating times. Differences in weighted ratios for $\mathrm{CO}_{2}$ emissions are due to equipment power, load factors, and project conditions. Figure 12 and Figure 13 present the mean weighted ratios of cost and $\mathrm{CO}_{2}$ emissions respectively, for all studied equipment configurations. The weighted ratio for $\mathrm{CO}_{2}$ emissions are in close agreement with those presented by Li and Lei (2010), with the exception of wheel-loaders, where our numbers are about three percentage points higher. This disparity can likely be explained by differences in engine sizes.

\subsubsection{Equipment utilization rates}

Operational efficiency measures such as the utilization rate of earthmoving equipment often correlate to lower $\mathrm{CO}_{2}$ emissions, costs, and duration (Krantz et al., 2019). Since Ezstrobe records utilization data of equipment, we are able to investigate whether our studied earthmoving operations display similar patterns. The utilization rate is the time spent non-idle as a percentage of total work time. Thus, the idle time considered may be conveniently summarized as queuing trucks, no trucks to load, and no material to spread. Table 7 shows average utilization rates for each equipment type by configuration and earthmoving zone.

\begin{tabular}{|c|c|c|c|c|c|c|c|c|c|}
\hline \multirow{2}{*}{ Zone } & \multirow{2}{*}{$\begin{array}{c}\text { Conf. } \\
\text { No. }\end{array}$} & \multicolumn{4}{|c|}{ Weighted ratio of total cost } & \multicolumn{4}{|c|}{ Weighted ratio of total emission } \\
\hline & & Truck & Loader & Exc. & Bull. & Truck & Loader & Exc. & Bull. \\
\hline \multirow{6}{*}{$\mathrm{D}$} & I & 0.595 & 0.095 & 0.1667 & 0.143 & 0.751 & 0.057 & 0.102 & 0.109 \\
\hline & II & 0.471 & 0.143 & 0.243 & 0.143 & 0.578 & 0.071 & 0.192 & 0.159 \\
\hline & III & 0.579 & 0.084 & 0.211 & 0.126 & 0.741 & 0.058 & 0.115 & 0.107 \\
\hline & IV & 0.609 & 0.097 & 0.171 & 0.122 & 0.699 & 0.064 & 0.113 & 0.146 \\
\hline & $\mathrm{V}$ & 0.545 & - & 0.227 & 0.227 & 0.792 & - & 0.048 & 0.159 \\
\hline & VI & 0.667 & - & 0.167 & 0.167 & 0.851 & - & 0.034 & 0.115 \\
\hline \multirow{6}{*}{$\mathrm{E}$} & I & 0.595 & 0.095 & 0.167 & 0.143 & 0.711 & 0.072 & 0.117 & 0.123 \\
\hline & II & 0.471 & 0.143 & 0.243 & 0.143 & 0.561 & 0.092 & 0.164 & 0.182 \\
\hline & III & 0.579 & 0.084 & 0.211 & 0.126 & 0.701 & 0.070 & 0.134 & 0.118 \\
\hline & IV & 0.609 & 0.097 & 0.171 & 0.122 & 0.694 & 0.0696 & 0.115 & 0.144 \\
\hline & $\mathrm{V}$ & 0.545 & - & 0.227 & 0.227 & 0.765 & - & 0.057 & 0.178 \\
\hline & VI & 0.667 & - & 0.167 & 0.167 & 0.819 & - & 0.043 & 0.137663 \\
\hline \multirow{6}{*}{ I } & I & 0.579 & 0.084 & 0.211 & 0.126 & 0.686 & 0.077 & 0.142 & 0.119 \\
\hline & II & 0.471 & 0.143 & 0.243 & 0.143 & 0.552 & 0.104 & 0.166 & 0.178 \\
\hline & III & 0.595 & 0.095 & 0.167 & 0.143 & 0.701 & 0.077 & 0.124 & 0.124 \\
\hline & IV & 0.609 & 0.097 & 0.171 & 0.122 & 0.683 & 0.076 & 0.120 & 0.145 \\
\hline & $\mathrm{V}$ & 0.545 & - & 0.227 & 0.227 & 0.749 & - & 0.063 & 0.187 \\
\hline & VI & 0.667 & - & 0.167 & 0.167 & 0.863 & - & 0.054 & 0.083 \\
\hline
\end{tabular}

Table 6. Cost and emissions weighted ratios of different equipment in the earthmoving project 


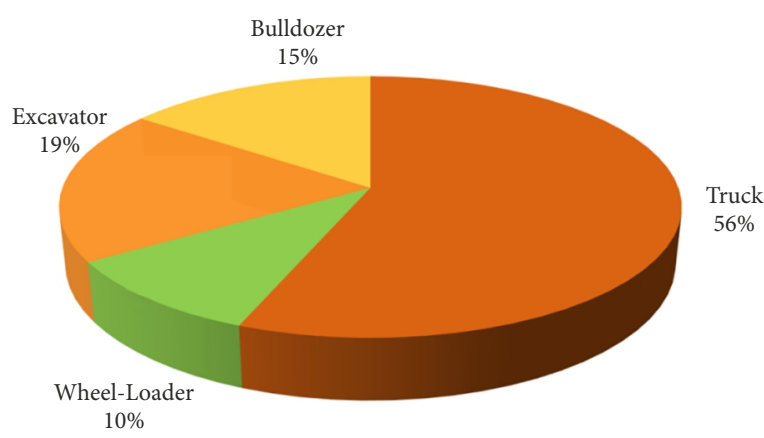

Figure 12. Cost weighted ratio for each equipment type

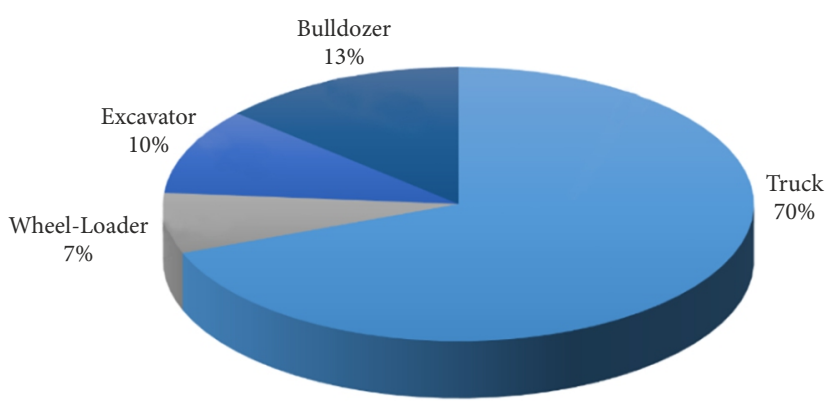

Figure 13. Weighted ratio of $\mathrm{CO}_{2}$ emissions by equipment type

Table 7. Total average utilization rates of equipment in different configurations and zones

\begin{tabular}{|c|c|c|c|c|c|c|c|c|c|c|c|}
\hline \multirow{2}{*}{ Zone } & \multirow{2}{*}{$\begin{array}{l}\text { Conf. } \\
\text { No. }\end{array}$} & \multicolumn{4}{|c|}{ Utilization Rate } & \multirow[t]{2}{*}{ Zone } & \multirow{2}{*}{$\begin{array}{l}\text { Conf. } \\
\text { No. }\end{array}$} & \multicolumn{4}{|c|}{ Utilization Rate } \\
\hline & & Truck & Loader & Exc. & Bull. & & & Truck & Loader & Exc. & Bull. \\
\hline \multirow{6}{*}{$\mathrm{D}$} & I & 0.802 & 0.660 & 0.804 & 0.197 & \multirow{3}{*}{ E } & IV & 0.762723 & 0.721 & 0.921 & 0.225 \\
\hline & II & 0.912 & 0.498 & 0.605 & 0.158 & & V & 0.856331 & - & 0.909 & 0.178 \\
\hline & III & 0.792 & 0.679 & 0.757 & 0.209 & & VI & 0.573 & - & 0.978 & 0.192 \\
\hline & IV & 0.804 & 0.656 & 0.803734 & 0.197 & \multirow{6}{*}{ I } & I & 0.574 & 0.715 & 0.951 & 0.229 \\
\hline & V & 0.852 & - & 0.751 & 0.147 & & II & 0.836 & 0.623 & 0.857 & 0.223 \\
\hline & VI & 0.707 & - & 0.949 & 0.186 & & III & 0.590 & 0.769 & 0.919 & 0.253 \\
\hline \multirow{3}{*}{$\mathrm{E}$} & I & 0.762 & 0.719 & 0.921 & 0.225 & & IV & 0.575 & 0.716 & 0.951 & 0.229 \\
\hline & II & 0.894 & 0.537 & 0.687 & 0.179 & & $\mathrm{~V}$ & 0.658 & - & 0.981 & 0.192 \\
\hline & III & 0.783 & 0.770 & 0.893 & 0.247 & & VI & 0.395 & - & 0.981 & 0.192 \\
\hline
\end{tabular}

The utilization rates correlate with the performance of uniform equipment configurations in terms of the earthmoving impact objectives in Table 4. Configuration III, which was seen as a particularly competitive configuration, balances the truck and excavator utilization rates at a high level in zones D and E, while also delivering the highest loader and bulldozer utilization rates. Zone I, which has considerably shorter hauling distances than zones $\mathrm{D}$ and $\mathrm{E}$, did not show similar balanced utilization rates for configuration III.

Approach C selected configurations II and III as optimal for hauling distances $<1.5 \mathrm{~km}$ and $>1.5 \mathrm{~km}$, respectively. Table 8 specifically considers the utilization rates according to these hauling distance intervals. The results show that excavators consistently have higher utilization rates than trucks for all earthmoving stations of hauling distances of $<1.5 \mathrm{~km}$, indicating the significance of excavators to ensure quicker throughput of trucks. This pattern is especially evident in zone I in Table 8 , where $~ 85 \%$ of its stations fall below the $<1.5 \mathrm{~km}$ hauling distance threshold.

For mass haulage distances $\geq 1.5 \mathrm{~km}$, configuration III exhibits a better balance between truck and excavator utilization rates. Trucks perform especially consistently at a higher utilization rate than for hauling distances $<1.5 \mathrm{~km}$. Similar to the results in Table 7, the wheel-loader and bulldozer utilization rates in configuration III are consistently the highest among all of the configurations.

\subsubsection{Utility values of earthmoving equipment configurations}

Utility theory is used here as decision support by assigning each equipment configuration a numerical index which can be described as the degree of fulfillment of the decision-maker's objectives or preferences. In other words, it presents a tool to measure the desirability of performance for activity and/or equipment used that offers a uniform scale to integrate tangible and intangible criteria (Ang \& Tang, 1984). Such "preference" indexes are values between a minimum to maximum limit that consist of quantity units translated into utility units (Keeney \& Raiffa, 1993). Utility functions can be represented as graphs, tables, or mathematical formulas (Clement, 1991). Furthermore, mathematical formulas of utility functions can be represented by the linear, logarithmic, or exponential expression (Marzouk \& Moselhi, 2003). Recently, this term has been investigated by Carmichael et al. (2018) regarding how carbon emissions can be better understood in construction operations. In this study Eqn (14) is used to represent the utility value based on the average utilization rate, type, number, and cost weighted ratio for each type of earthmoving equipment, total material quantity, and costs. Therefore, the utility index here considers interconnected relationships between the time, cost, and work volume for each item of equipment and fleet equipment configuration. Keeney and Raiffa (1993) recommended 
Table 8. Average utilization rates for each item of equipment per configuration and zones based on haul distances

\begin{tabular}{|c|c|c|c|c|c|c|c|c|c|c|c|}
\hline \multirow{2}{*}{ Zone } & \multirow{2}{*}{$\begin{array}{c}\text { Conf. } \\
\text { No. }\end{array}$} & \multicolumn{4}{|c|}{ Utilization rate for hauling distances $<1.5 \mathrm{~km}$} & \multirow{2}{*}{ Zone } & \multirow{2}{*}{$\begin{array}{c}\text { Conf. } \\
\text { No. }\end{array}$} & \multicolumn{4}{|c|}{ Utilization rate for hauling distances $\geq 1.5 \mathrm{~km}$} \\
\hline & & Truck & Loader & Exc. & Bull. & & & Truck & Loader & Exc. & Bull. \\
\hline \multirow{6}{*}{$\mathrm{D}$} & I & 0.459 & 0.757 & 0.993 & 0.242 & \multirow{6}{*}{$\mathrm{D}$} & I & 0.917 & 0.628 & 0.741 & 0.182 \\
\hline & II & 0.747 & 0.697 & 0.974 & 0.258 & & II & 0.966 & 0.431 & 0.483 & 0.124 \\
\hline & III & 0.480 & 0.832 & 0.969 & 0.270 & & III & 0.896 & 0.628 & 0.685529 & 0.188 \\
\hline & IV & 0.461 & 0.758 & 0.993 & 0.241 & & IV & 0.918 & 0.622 & 0.741 & 0.182 \\
\hline & $\mathrm{V}$ & 0.479 & - & 0.998 & 0.195 & & V & 0.977 & - & 0.669 & 0.131 \\
\hline & VI & 0.287 & - & 0.998 & 0.195 & & VI & 0.846 & - & 0.934 & 0.183 \\
\hline \multirow{6}{*}{$\mathrm{E}$} & I & 0.428 & 0.763 & 0.994 & 0.243 & \multirow{6}{*}{$\mathrm{E}$} & I & 0.846 & 0.708970 & 0.903 & 0.219 \\
\hline & II & 0.694 & 0.704714 & 0.982731 & 0.261 & & II & 0.944 & 0.494835 & 0.613 & 0.159 \\
\hline & III & 0.449 & 0.842 & 0.988 & 0.275 & & III & 0.867 & 0.752521 & 0.869 & 0.240 \\
\hline & IV & 0.427 & 0.763 & 0.994 & 0.243 & & IV & 0.846 & 0.711236 & 0.904 & 0.220 \\
\hline & V & 0.434 & - & 0.999 & 0.196 & & V & 0.962 & - & 0.887 & 0.174 \\
\hline & VI & 0.260 & - & 0.999 & 0.196 & & VI & 0.651 & - & 0.973 & 0.191 \\
\hline \multirow{6}{*}{ I } & I & 0.544 & 0.716 & 0.955 & 0.230 & \multirow{6}{*}{ I } & I & 0.754 & 0.713 & 0.932 & 0.226 \\
\hline & II & 0.823 & 0.643 & 0.885 & 0.231 & & II & 0.912 & 0.504 & 0.688 & 0.178 \\
\hline & III & 0.558 & 0.775 & 0.920 & 0.254 & & III & 0.782 & 0.735 & 0.91456 & 0.249 \\
\hline & IV & 0.545 & 0.716 & 0.954 & 0.230 & & IV & 0.753 & 0.714 & 0.932 & 0.226 \\
\hline & $\mathrm{V}$ & 0.616 & - & 0.982 & 0.193 & & $\mathrm{~V}$ & 0.907 & - & 0.973 & 0.191 \\
\hline & VI & 0.369 & - & 0.982 & 0.193 & & VI & 0.545 & - & 0.975 & 0.191 \\
\hline
\end{tabular}

that the most desirable scenario corresponds to the highest utility value. In our case the equipment configuration utilization rates of $100 \%$ and $10 \%$ represent utility values between $0.1-1$. The utility values for the four performance measures are calculated as follows:

$$
U_{T E C}=\left[\frac{\sum_{i=1}^{n}\left(U_{a r} \cdot N_{e} \cdot C_{w r}\right)_{i}}{T_{N E} \cdot r_{d}}\right] \cdot\left[\frac{T_{Q}}{T_{E C}}\right],
$$

where $U_{T E C}=$ utility value for earthmoving operations efficiency per equipment configuration, $U_{a r}=$ average utilization rates per equipment type in an equipment configuration, $N_{e}=$ number of equipment types per configuration, $C_{w r}=$ cost weighted ratio for the specific type of equipment against total cost of earthmoving operations (decimal), and where $i=1,2,3, \ldots, n ; n=$ the total different types of equipment used in each earthmoving configuration. $T_{N E}=$ total number of items of earthmoving equipment used in a specific earthmoving configuration, and $r_{d}=$ adjusted factor to the range of utility index distribution (0.037). $T_{Q}=$ volume of earthmoving materials hauled by earthmoving configuration, and $T_{E C}=$ total cost of earthmoving operations by configuration. For instance, the utility values computations for a part of earthmoving operations are shown in Example (1).

Example (1): the computing of utility value for one of the six earthmoving equipment configurations that was used in earthmoving zone (E), based on the outputs of allocated approach (A). Zone E consisted of 10 earthmoving stations that involved earthmoving quantities of $\left(32459 \mathrm{~m}^{3}\right)$, and with a description of their operational parameters and costs is shown in Table 9.

Utility value computation for earthmoving equipment configuration (III):

$U_{T E C}=\left[\frac{\sum_{i=1}^{4}\left(U_{a r} \cdot N_{e} \cdot C_{w r}\right)_{i}}{9^{\star} 0.037}\right] *\left[\frac{32459}{644497.9}\right] ;$

$U_{\text {TEC }}=\left[\frac{\left(0.763^{*} 5^{*} 0.579\right)+\left(0.893^{*} 2^{*} 0.211\right)+\left(0.770^{*} 1^{*} 0.084\right)+\left(0.247^{*} 1^{*} 0.126\right)}{9 * 0.037}\right] *$

$\left[\frac{32459}{644497.9}\right]=0.617$

Further, Table 10 shows that, based on the outputs of approach C, equipment configurations II and III have the highest utility values for hauling distances $(<1.5 \mathrm{~km})$ and $(\geq 1.5 \mathrm{~km})$, respectively. Configuration III has the highest utility value among uniform equipment configuration (i.e., approach A) in zones D and E, while configuration II has the highest rate in zone I that have twenty one' earthmoving stations with a total earthworks quantity of $\left(71358 \mathrm{~m}^{3}\right)$, involving $\left(51215 \mathrm{~m}^{3}\right)$ of the total quantity hauled for distances between $0.1 \mathrm{~km}$ to less than $1.5 \mathrm{~km}$, and $\left(20143 \mathrm{~m}^{3}\right)$ hauled to distances up to $(1.5 \mathrm{~km})$ and less than $(2 \mathrm{~km})$. Hauling distances of between $(0.1-4.5 \mathrm{~km})$ are found on other earthmoving zones (D and $\mathrm{E}$ ). This is in agreement with the utilization rates and is likely caused by $85 \%$ of the hauling distances in the zone being $<1.5 \mathrm{~km}$. These results show that utility values may also efficiently support the selection of equipment configurations related to mass hauling distances. 
Table 9. Different parameters relating to equipment configurations in zone A

\begin{tabular}{|c|c|c|c|c|c|c|c|c|c|c|c|c|c|}
\hline \multirow{2}{*}{ 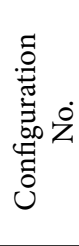 } & \multirow{2}{*}{ 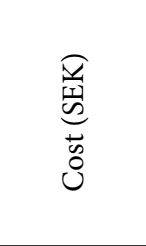 } & \multicolumn{4}{|c|}{$\begin{array}{c}\text { No. of each equipment item } \\
\text { in configuration }\end{array}$} & \multicolumn{4}{|c|}{ Average utilization rate of } & \multicolumn{4}{|c|}{ Cost weighted impact of } \\
\hline & & $\underset{ت}{\underline{Z}}$ & 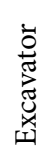 & 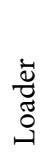 & 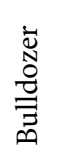 & $\frac{\tilde{y}}{\underline{\underline{Z}}}$ & 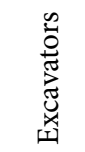 & $\begin{array}{l}\dot{\tilde{U}} \\
\stackrel{\tilde{\sigma}}{0} \\
\end{array}$ & 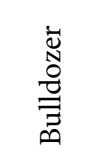 & $\frac{\mathscr{n}}{\underline{\underline{U}}}$ & 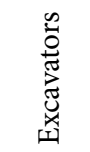 & $\begin{array}{l}\stackrel{\tilde{D}}{\tilde{\Xi}} \\
\stackrel{\sigma}{0}\end{array}$ & 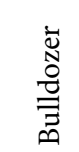 \\
\hline I & 849766 & 5 & 2 & 1 & 1 & 0.763 & 0.921 & 0.719 & 0.225 & 0.595 & 0.167 & 0.095 & 0.143 \\
\hline II & 773934.4 & 3 & 2 & 1 & 1 & 0.894 & 0.687 & 0.537 & 0.179 & 0.471 & 0.243 & 0.143 & 0.143 \\
\hline III & 644497.9 & 5 & 2 & 1 & 1 & 0.783 & 0.893 & 0.770 & 0.247 & 0.579 & 0.211 & 0.084 & 0.126 \\
\hline IV & 828927.1 & 5 & 2 & 1 & 1 & 0.763 & 0.922 & 0.722 & 0.225 & 0.609 & 0.171 & 0.098 & 0.122 \\
\hline $\mathrm{V}$ & 916867.4 & 3 & 1 & - & 1 & 0.856 & 0.909 & - & 0.178 & 0.545 & 0.227 & 0.095 & 0.227 \\
\hline VI & 1147619.6 & 5 & 1 & - & 1 & 0.573 & 0.978 & - & 0.192 & 0.667 & 0.167 & 0.143 & 0.167 \\
\hline
\end{tabular}

Table 10. Utility values per equipment configuration in each zone

\begin{tabular}{|c|c|c|c|c|}
\hline \multirow[t]{2}{*}{ Zone } & \multirow{2}{*}{$\begin{array}{l}\text { Conf. } \\
\text { No. }\end{array}$} & \multirow{2}{*}{$\begin{array}{l}\text { Utility value for earthmoving configurations selected } \\
\text { in Uniform combination approach (A) }\end{array}$} & \multicolumn{2}{|c|}{$\begin{array}{l}\text { Utility value for earthmoving configurations selected } \\
\text { in approach (C) }\end{array}$} \\
\hline & & & hauling distances $<1.5 \mathrm{~km}$ & hauling distances $\geq 1.5 \mathrm{~km}$ \\
\hline \multirow{6}{*}{$\mathrm{D}$} & I & 0.38141 & 0.38594 & 0.38047 \\
\hline & II & 0.36987 & 0.71626 & 0.31722 \\
\hline & III & 0.47656 & 0.53399 & 0.46398 \\
\hline & IV & 0.39503 & 0.39919 & 0.39419 \\
\hline & $\mathrm{V}$ & 0.42107 & 0.51266 & 0.40252 \\
\hline & VI & 0.40147 & 0.27471 & 0.44046 \\
\hline \multirow{6}{*}{$\mathrm{E}$} & I & 0.46026 & 0.37496 & 0.47277 \\
\hline & II & 0.48535 & 0.70187 & 0.42081 \\
\hline & III & 0.61737 & 0.52782 & 0.62453 \\
\hline & IV & 0.47709 & 0.38639 & 0.49068 \\
\hline & $\mathrm{V}$ & 0.57667 & 0.49764 & 0.58134 \\
\hline & VI & 0.37463 & 0.26478 & 0.40058 \\
\hline \multirow{6}{*}{ I } & $\mathrm{I}$ & 0.42225 & 0.41145 & 0.48554 \\
\hline & II & 0.62923 & 0.68424 & 0.51824 \\
\hline & III & 0.57627 & 0.55936 & 0.67289 \\
\hline & IV & 0.43488 & 0.42330 & 0.50275 \\
\hline & $\mathrm{V}$ & 0.33715 & 0.55805 & 0.18944 \\
\hline & VI & 0.31266 & 0.30350 & 0.36761 \\
\hline
\end{tabular}

\subsection{Summarized results and discussion}

In this study, DES can essentially be seen as part of the search for an optimum allocation of equipment in earthmoving projects; the intention is to offer a range of possible solutions that could help in making decisions about the final configurations that can support the most effective mass haulage plan for any major project, all factors considered. It is important to note that certain changes in the configurations of earthmoving equipment will influence project duration, costs, and environmental impacts. Therefore, a proper DES should provide efficient planning techniques for equipment selection in earthmoving operations that have positively improved costs and/ or broken other constraints. The environmental impacts are considered as variables in the simulation stage of the
PSED and estimated directly from the DES model at each scenario based on the relevant assessment formula for each piece of equipment that has considered machinery characteristics and specific site conditions. Furthermore, here the simulation results have an agreement with the outputs of analytical solutions to previous researches that stated the minimize emissions consider also as a way to minimize cost of earthmoving operations (Kaboli \& Carmichael, 2014; Carmichael et al., 2014). Thus, the planner should note the potential for this stage to reduce these impacts, too. The simulation mechanism could provide a result with satisfactory performance outputs without imposing on other objectives, which can be an option for a planner to consider when decision-making. Although this step is primarily important in assessing the overall earthmoving project impacts during the planning stage, 
the outputs of this step can nevertheless be considered as significant references or benchmarks for monitoring and evaluating the performances of these operations during execution stages.

The results of the three alternative approaches for allocating equipment configurations evaluated in this case study are summarized in Table 11, Figure 14, and Figure 15. Approach A, which entails using one configuration for the whole earthmoving process, showed that configuration III was superior to the other configurations with regard to duration, costs, energy use, and $\mathrm{CO}_{2}$ emissions. Approach $\mathrm{B}$, which uses mixed configurations for each earthmoving zone, showed potential for further reducing $\mathrm{CO}_{2}$ emissions by $\sim 6 \%$, and energy use by $\sim 7 \%$, but adding $\sim 0.1 \%$ in costs and $\sim 21 \%$ in duration compared with approach A. Approach $\mathrm{C}$ was used to allocate equipment configurations on the basis of hauling distances. It was found that configuration II was superior in terms of costs and $\mathrm{CO}_{2}$ emissions at distances $<1.5 \mathrm{~km}$, whereas configuration III was superior at distances $\geq 1.5 \mathrm{~km}$. Compared to approach $\mathrm{B}$, approach $\mathrm{C}$ enabled a reduction of $\mathrm{CO}_{2}$ emissions, energy use, costs, and execution time by $1.4 \%$, $1.1 \%, 3.6 \%$, and $\sim 10.5 \%$, respectively. In comparison with the optimum configuration from approach A (i.e., configuration III), this approach yielded a reduction of $\sim 3.4 \%$ in costs, $\sim 8.1 \%$ in energy use, and $~ 7.4 \%$ in $\mathrm{CO}_{2}$, while increasing duration of $\sim 10 \%$. Tables 4 and 10 also show a significant term related to construction operations that is called a function unit of earthmoving impact for each target parameter (i.e. it is used to identify the impact for each target value per cubic meter of material produced from the earthmoving operations), which is important in this study for two reasons: firstly, it can show the consistency of relation between these values and the totality of each impact; secondly, it shows the influence of earthmoving volumes $\left(\mathrm{m}^{3}\right)$ for each station on the total impacts from a zone, for instance, the situation of earthmoving operations in zone I.

\section{Conclusions and implications}

This study set out to propose a comprehensive model, called PSED, to help reduce the duration, costs, and GHG emissions of earthmoving processes undertaken during major construction/infrastructure projects. The model was used to identify and allocate suitable equipment configurations to an earthmoving project and its different earthmoving zones. A case study consisting of 43 earthmoving stations of varying character was conducted to demonstrate the ability of the model to quantify the aforementioned objectives. Earthmoving equipment configurations were allocated based on their performance according to the following approaches: (A) earthmoving zones, the more detailed (B) earthmoving stations, and (C) hauling distances.

Table 11. Results in terms of time, costs, and environmental impacts of the studied approaches

\begin{tabular}{|c|c|c|c|c|c|c|c|c|c|c|c|c|}
\hline \multirow{2}{*}{$\begin{array}{c}\text { Configuration } \\
\text { No. }\end{array}$} & \multicolumn{2}{|c|}{ Time } & \multicolumn{2}{|c|}{ Cost } & \multicolumn{2}{|c|}{ Energy } & \multicolumn{2}{|c|}{ Emissions $\left(\mathrm{CO}_{2}\right)$} & \multicolumn{4}{|c|}{$\begin{array}{l}\text { Profit of approach }(\mathrm{C}) \text { comparing } \\
\text { with all configurations proposed }\end{array}$} \\
\hline & hour $/ \mathrm{m}^{3}$ & hours & $\mathrm{SEK} / \mathrm{m}^{3}$ & $\left(1000^{\star}\right.$ SEK $)$ & $\mathrm{MJ} / \mathrm{m}^{3}$ & $\left(1000^{\star} \mathrm{MJ}\right)$ & $\mathrm{kg} / \mathrm{m}^{3}$ & $\left(1000^{\star} \mathrm{kg}\right)$ & Time & Cost & Energy & Emission \\
\hline I & 0.0033 & 494.7 & 24.8 & 4155.1 & 54.4 & 8444.6 & 3.95 & 611.6 & $25.2 \%$ & $26.2 \%$ & $12.8 \%$ & $13.0 \%$ \\
\hline II & 0.0034 & 513.9 & 21.9 & 3597.2 & 54.7 & 8359.4 & 3.97 & 605.3 & $28.0 \%$ & $14.7 \%$ & $11.9 \%$ & $12.1 \%$ \\
\hline Approach (A) & 0.0023 & 334.1 & 22.9 & 3173.7 & 52.4 & 8005.7 & 3.79 & 574.3 & $-10.7 \%$ & $3.4 \%$ & $8.0 \%$ & $7.5 \%$ \\
\hline IV & 0.0033 & 494.8 & 24.2 & 4057.3 & 53.5 & 8341.6 & 3.89 & 605.3 & $25.2 \%$ & $24.4 \%$ & $11.7 \%$ & $12.1 \%$ \\
\hline V & 0.0067 & 1038.4 & 29.6 & 4568.8 & 56.3 & 8740.7 & 4.02 & 622.7 & $64.4 \%$ & $32.8 \%$ & $15.8 \%$ & $14.6 \%$ \\
\hline VI & 0.0059 & 906.8 & 36.0 & 5440.9 & 62.8 & 9631.9 & 4.54 & 692.5 & $59.2 \%$ & $43.6 \%$ & $23.6 \%$ & $23.2 \%$ \\
\hline Approach (B) & 0.0028 & 412.9 & 21.7 & 3177.8 & 49.7 & 7443.3 & 3.80 & 539.6 & $10.5 \%$ & $3.5 \%$ & $1.1 \%$ & $1.4 \%$ \\
\hline Approach (C) & 0.0025 & 370.15 & 20.6 & 3068.0 & 49.3 & 7361.5 & 3.57 & 532.0 & - & - & - & - \\
\hline
\end{tabular}

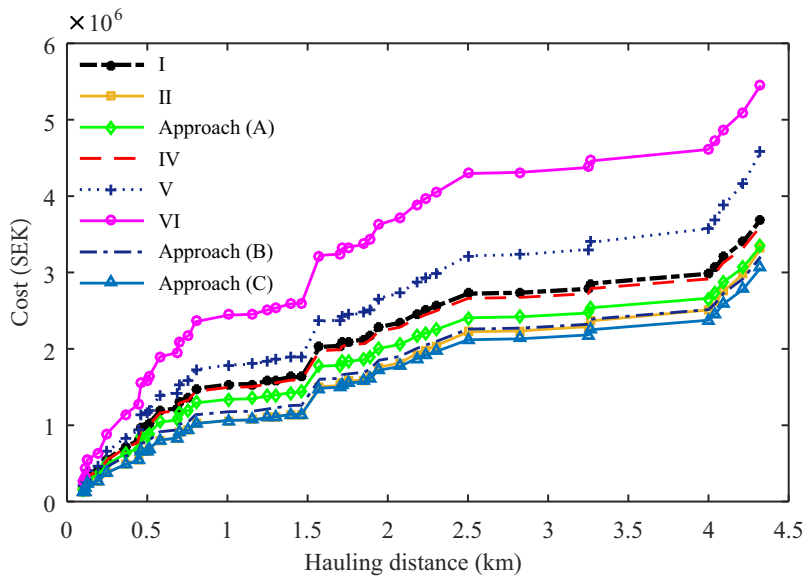

Figure 14. Cumulative earthmoving costs per configuration

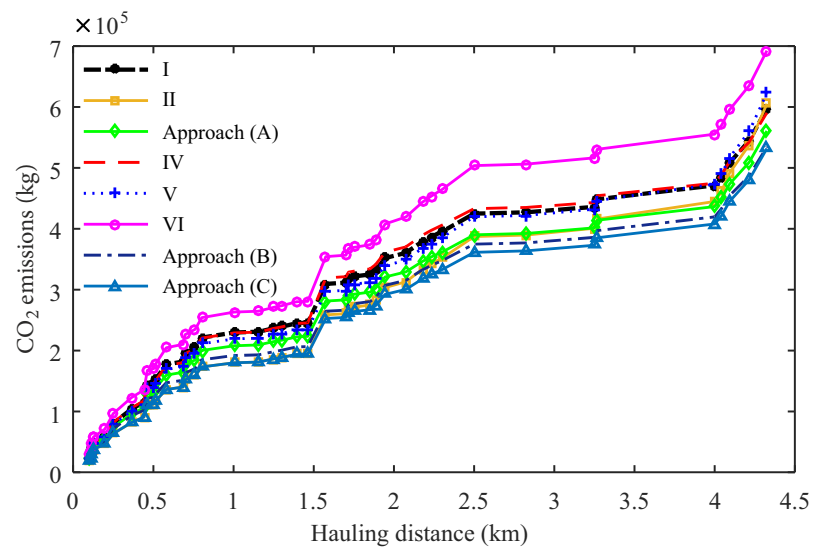

Figure 15. Cumulative earthmoving $\mathrm{CO}_{2}$ emissions per configuration 
The results of approach A showed considerable differences between the initially identified configurations in terms of costs, duration, $\mathrm{CO}_{2}$ emissions, and energy use. Thus, the approach may be powerful if allocating one equipment configuration to a given earthmoving project or single zone. Approach B could potentially generate further savings in terms of all objectives, although our case study only showed reductions in terms of $\mathrm{CO}_{2}$ emissions and energy use, with the same range of costs and increased duration compared to approach A. Approach C investigated the results by hauling distance, and provided in our case study an intersection point between configurations II and III at hauling distances of around $1.5 \mathrm{~km}$ both with regard to costs and $\mathrm{CO}_{2}$ emissions. Furthermore, this approach turned out to be superior to the other approaches in terms of costs, energy use, and $\mathrm{CO}_{2}$ emissions. Functional units of earthmoving operations' impact can play an important role in providing the simplest way to allocate equipment for earthmoving zones that have stations with harmonic earthmoving characteristics (e.g., quantity and hauling distances).

To substantiate the case study results, we studied the overall impact of equipment types, the utilization rates by equipment type, and the utility of each configuration. Utility theory is widely used to support decisions in construction management and should indicate the performance level of each configuration in terms of the objectives considered. In our case the highest utility values corresponded with the best performing equipment configurations. The interaction between truck and excavator utilization rates is another potentially significant indication to consider for the overall performance of equipment configurations. The results of configurations II and III indicated that high and balanced truck and excavator utilization rates may be a powerful way of reducing adverse project impacts. Carmichael and Mustaffa (2018) and Carmichael et al. (2018) have drawn similar conclusions regarding optimum performance in earthmoving configuration by balancing the excavator and truck utilizations while considering the percentages of emissions and costs of the different equipment. Increased truck utilization rates are particularly important in decreasing negative project impacts, especially in the case of hauling distances of $<1.5 \mathrm{~km}$, demonstrated by the performance of configuration II. The importance of trucks was further demonstrated by their overall cost and $\mathrm{CO}_{2}$ emissions impact as seen in Figure and Figure , indicating the necessity of putting more effort into the primary selection of configurations. Worth noting here is the considerably higher cost than environmental impact of the excavator both when single and double loading areas are used. This suggests that the choice of excavator may be particularly important when managing project costs. Bulldozers also display a significant effect on the configuration performance as high utilization rates correlate with higher overall performance.

The model may be attractive for contractors seeking to manage impact reductions and the necessary tradeoff decisions (Ahn et al., 2009), particularly since costs were included as an objective (Jukic \& Carmichael, 2016). Given that approach $C$ was superior to the other approaches, the simple rule-based results derived from it may simplify implementation and increase understanding among equipment operators, site managers, and others at the construction site. Indeed, simplicity is crucial since construction projects are often burdened with onerous cost and time constraints, severely limiting the ability of the project organization to adopt novel and complex guidelines or approaches (Jacobsson \& Linderoth, 2010). But, even though the results derived are simple, running the PSED model is complex, and consequently usage of the tool may be most suitable mainly for central organizations of construction companies rather than for those on the ground. In the short term it may be used to appoint equipment configurations to projects (together with the simple rulebased guidelines); in the longer term it could also support strategic decisions regarding equipment acquisitions and management of the equipment fleet.

In a nutshell, the equipment weighted impacts (cost and emissions) and utilization rates, and configuration utility value are typically considered the important terms of such projects; as stated earlier, these factors were incorporated here for the following reasons: (i) to validate the planning outputs of PSED by comparison with impact ratios for earthmoving equipment in other researches, as well as the significance of the utilization rate to mitigate impacts; and (ii) to support the adopted approach in this study of selecting configurations that show agreement with utility theory.

The case study considered a wide range of various effects on earthmoving operations, for example, the density of materials excavated/hauled, payload, grade, and rolling resistance for trucks, as well as the haulage distance from different points into/from/to the road construction project. However, to enable the approach to be applied more generally, more cases studies are needed, particularly involving a greater number of equipment configurations and alternative fuels. Such studies may be useful in identifying additional simple rule-based equipment allocation approaches to enable wider implementation among organizations involved in planning and executing major construction projects.

\section{Acknowledgements}

The authors would like to thank the Development Fund of the Swedish Construction Industry (SBUF), and supported by NCC AB. The first author would also like to thank the Iraqi Ministry of Higher Education and Scientific Research, and the Department of Civil Engineering in the College of Engineering at the University of Babylon for their financial support under the International doctoral scholarship program.

\section{Funding}

This work was supported by the Lulea University of Technology. 


\section{Author contributions}

Jassim as the main author, formulated the main idea, developed the model, conducted the simulations, calculations, and analysis and wrote most of the paper. Krantz collected case study data, wrote the literature review, helped refine the overall research idea, and reviewed and revised the manuscript. All co-authors provided feedback and support.

\section{Disclosure statement}

No potential conflict of interest was reported by the authors.

\section{References}

Abolhasani, S., Frey, H. C., Kim, K., Rasdorf, W., Lewis, P., \& Pang, S. (2008). Real-world in-use activity, fuel use, and emissions for nonroad construction vehicles: a case study for excavators. Journal of the Air \& Waste Management Association, 58(8), 1033-1046. https://doi.org/10.3155/10473289.58.8.1033

Ahn, C., Martinez, J. C., Rekapalli, P. V., \& Peña-Mora, F. A. (2009). Sustainability analysis of earthmoving operations. In Proceedings of the 2009 Winter Simulation Conference (WSC), Austin, TX, USA. https://doi.org/10.1109/WSC.2009.5429656

Ahn, C., Xie, H., Lee, S., Abourizk, S., \& Peña-Mora, F. (2010). Carbon footprints analysis for tunnel construction processes in the preplanning phase using collaborative simulation. In Construction Research Congress 2010: Innovation for Reshaping Construction Practice. https://doi.org/10.1061/41109(373)154

Akadiri, P. O., Chinyio, E. A., \& Olomolaiye, P. O. (2012). Design of a sustainable building: A conceptual framework for implementing sustainability in the building sector. Buildings, 2(2), 126-152. https://doi.org/10.3390/buildings2020126

Ang, A. H. S., \& Tang, W. H. (1984). Probability concepts in engineering planning and design. Vol. 2: Decision, risk, and reliability. John Wiley \& Sons.

Ariaratnam, S. T., Piratla, K., Cohen, A., \& Olson, M. (2013). Quantification of sustainability index for underground utility infrastructure projects. Journal of Construction Engineering and Management, 139(12), A4013002.

https://doi.org/10.1061/(ASCE)CO.1943-7862.0000763

Avetisyan, H. G., Miller-Hooks, E., \& Melanta, S. (2011). Decision models to support greenhouse gas emissions reduction from transportation construction projects. Journal of Construction Engineering and Management, 138(5), 631-641. https://doi.org/10.1061/(ASCE)CO.1943-7862.0000477

Bogenberger, C., Dell'Amico, M., Fuellerer, G., Hoefinger, G., Iori, M., Novellani, S., \& Panicucci, B. (2015). Two-phase earthwork optimization model for highway construction. Journal of Construction Engineering and Management, 141(6), 05015003.

https://doi.org/10.1061/(ASCE)CO.1943-7862.0000973

Carmichael, D. G., Bartlett, B. J., \& Kaboli, A. S. (2014). Surface mining operations: coincident unit cost and emissions. International Journal of Mining, Reclamation and Environment, 28(1), 47-65. https://doi.org/10.1080/17480930.2013.772699

Carmichael, D. G., \& Mustaffa, N. K. (2018). Emissions and production penalties/bonuses associated with non-standard earthmoving loading policies. Construction Innovation, 18(2). https://doi.org/10.1108/CI-05-2017-0047
Carmichael, D. G., Mustaffa, N. K., \& Shen, X. (2018). A utility measure of attitudes to lower-emissions production in construction. Journal of Cleaner Production, 202, 23-32. https://doi.org/10.1016/j.jclepro.2018.08.086.

Carmichael, D. G., Shen, X., \& Peansupap, V. (2019). The relationship between heavy equipment cost efficiency and cleaner production in construction. Journal of Cleaner Production, 211, 521-529. https://doi.org/10.1016/j.jclepro.2018.11.167

Ciscar, J. C., Iglesias, A., Feyen, L., Szabó, L., Van Regemorter, D., Amelung, B., Nicholls, R., Watkiss, P., Christensen, O. B., Dankers, R., \& Garrote, L. (2011). Physical and economic consequences of climate change in Europe. Proceedings of the National Academy of Sciences of the United States of America, 108(7), 2678-2683. https://doi.org/10.1073/pnas.1011612108

Clement, R. T. (1991). Making hard decisions: An introduction to decision analysis. Plus-Kent Publishing Company.

Deb, K. (2001). Multi-objective optimization using evolutionary algorithms. John Wiley \& Sons.

Dongier, P., \& Lovei, L. (2006). Infrastructure at the crossroads: lessons from 20 years of World Bank experience. The World Bank Group.

European Commission. (2003). Directive 2003/87/EC of the European Parliament and of the Council of 13 October 2003 Establishing a scheme for greenhouse gas emission allowance trading within the community and amending Council Directive 96/61/EC. https://eur-lex.europa.eu/legal-content/EN/ TXT/?uri=CELEX\%3A32003L0087

Fonseca, C. M., \& Fleming, P. J. (1993). Genetic algorithms for multiobjective optimization: Formulation discussion and generalization. In Genetic Algorithms: Proceedings of the Fifth International Conference (pp. 416-423). Morgan Kaufmann.

Fordham, D. A., Resit Akçakaya, H., Araújo, M. B., Elith, J., Keith, D. A., Pearson, R., Auld, T. D., Mellin, C., Morgan, J. W., Regan, T. J., \& Tozer, M. (2012). Plant extinction risk under climate change: are forecast range shifts alone a good indicator of species vulnerability to global warming? Global Change Biology, 18(4), 1357-1371. https://doi.org/10.1111/j.1365-2486.2011.02614.x

Frey, H. C., Rasdorf, W., \& Lewis, P. (2010). Comprehensive field study of fuel use and emissions of nonroad diesel construction equipment. Transportation Research Record: Journal of the Transportation Research Board, 2158(1), 69-76. https://doi.org/10.3141/2158-09

Goh, C. K., Tan, K. C., Liu, D., \& Chiam, S. C. (2010). A competitive and cooperative co-evolutionary approach to multiobjective particle swarm optimization algorithm design. European Journal of Operational Research, 202(1), 42-54. https://doi.org/10.1016/j.ejor.2009.05.005

González, V., \& Echaveguren, T. (2012). Exploring the environmental modeling of road construction operations using discrete-event simulation. Automation in Construction, 24, 100-110. https://doi.org/10.1016/j.autcon.2012.02.011

Grann, H. (1997). The industrial symbiosis at Kalundborg, Denmark. In The industrial green game. Implications for environmental design and management (pp. 117-123). National Academy Press.

Gwak, H., Seo, J., \& Lee, D. (2018). Optimal cut-fill pairing and sequencing method in earthwork operation. Automation in Construction, 87, 60-73.

https://doi.org/10.1016/j.autcon.2017.12.010

Horn, J., Nafpliotis, N., \& Goldberg, D. E. (1994). A niched Pareto genetic algorithm for multiobjective optimization. In Proceedings of the First IEEE Conference on Evolutionary Computation. IEEE World Congress on Computational Intelligence. Orlando, FL, USA. https://doi.org/10.1109/ICEC.1994.350037 
Hunkeler, D., \& Rebitzer, G. (2005). The future of life cycle assessment. The International Journal of Life Cycle Assessment, 10(5), 305-308. https://doi.org/10.1065/lca2005.09.001

Jacobsson, M., \& Linderoth, H. C. (2010). The influence of contextual elements, actors' frames of reference, and technology on the adoption and use of ICT in construction projects: a Swedish case study. Construction Management and Economics, 28(1), 13-23. https://doi.org/10.1080/01446190903406154

Jassim, H., Lu, W., \& Olofsson, T. (2017). Predicting energy consumption and $\mathrm{CO} 2$ emissions of excavators in earthwork operations: an artificial neural network model. Sustainability, 9(7), 1257. https://doi.org/10.3390/su9071257

Jassim, H. S., Lu, W., \& Olofsson, T. (2018a). Assessing energy consumption and carbon dioxide emissions of off-highway trucks in earthwork operations: An artificial neural network model. Journal of Cleaner Production, 198, 364-380. https://doi.org/10.1016/j.jclepro.2018.07.002

Jassim, H. S., Lu, W., \& Olofsson, T. (2018b). Quantification of energy consumption and carbon dioxide emissions during excavator operations. In I. Smith, \& B. Domer (Eds.), Lecture Notes in Computer Science: Vol. 10863. Advanced Computing Strategies for Engineering. EG-ICE 2018. Springer. https://doi.org/10.1007/978-3-319-91635-4_22

Jassim, H. S., Lu, W., \& Olofsson, T. (2019). Determining the environmental impact of material hauling with wheel loaders during earthmoving operations. Journal of the Air \& Waste Management Association, 69(10), 1195-1214. https://doi.org/10.1080/10962247.2019.1640805

Jukic, D., \& Carmichael, D. G. (2016). Emission and cost effects of training for construction equipment operators: a field study. Smart and Sustainable Built Environment, 5(2), 96-110. https://doi.org/10.1108/SASBE-11-2015-0040

Kaboli, A. S., \& Carmichael, D. G. (2014). Truck dispatching and minimum emissions earthmoving. Smart and Sustainable Built Environment, 3(2), 170-186. https://doi.org/10.1108/SASBE-10-2013-0050

Karimi, M. S., Mousavi, S. J., Kaveh, A., \& Afshar, A. (2007). Fuzzy optimization model for earthwork allocations with imprecise parameters. Journal of Construction Engineering and Management, 133(2), 181-190. https://doi.org/10.1061/(ASCE)0733-9364(2007)133:2(181)

Keeney, R. L., \& Raiffa, H. (1993). Decisions with multiple objectives: preferences and value trade-offs. Cambridge University Press. https://doi.org/10.1017/CBO9781139174084

Kennedy, J., \& Eberhart, R. C. (1995). Particle swarm optimization. In Proceedings of IEEE International Conference on $\mathrm{Neu}$ ral Networks (pp. 1942-1948).

https://doi.org/10.1109/ICNN.1995.488968

Kim, B., \& Kim, Y. (2016). Configuration of earthwork equipment considering environmental impacts, cost and schedule. Journal of Civil Engineering and Management, 22(1), 73-85. https://doi.org/10.3846/13923730.2014.897964

Kim, B., Lee, H., Park, H., \& Kim, H. (2011). Greenhouse gas emissions from onsite equipment usage in road construction. Journal of Construction Engineering and Management, 138(8), 982-990.

https://doi.org/10.1061/(ASCE)CO.1943-7862.0000515

Kim, B., Lee, H., Park, H., \& Kim, H. (2012). Estimation of greenhouse gas emissions from land-use changes due to road construction in the Republic of Korea. Journal of Construction Engineering and Management, 139(3), 339-346.

https://doi.org/10.1061/(ASCE)CO.1943-7862.0000620

Klanfar, M., Korman, T., \& Kujundžić, T. (2016). Fuel consumption and engine load factors of equipment in quarrying of crushed stone. Tehnički vjesnik/Technical Gazette, 23(1), 163169. https://doi.org/10.17559/TV-20141027115647

Konak, A., Coit, D. W., \& Smith, A. E. (2006). Multi-objective optimization using genetic algorithms: A tutorial. Reliability Engineering \& System Safety, 91(9), 992-1007. https://doi.org/10.1016/j.ress.2005.11.018

Krantz, J., Feng, K., Larsson, J., \& Olofsson, T. (2019). 'Eco-Hauling' principles to reduce carbon emissions and the costs of earthmoving - A case study. Journal of Cleaner Production, 208, 479-489. https://doi.org/10.1016/j.jclepro.2018.10.113

Kubsh, J. (2017). Diesel retrofit technologies and experience for on-road and off-road vehicles. International Council on Clean Transportation (ICCT). https://theicct.org/sites/default/files/publications/Diesel-Retrofits_ICCT_ConsultantReport_13062017_vF.pdf.

Lajunen, A., Sainio, P., Laurila, L., Pippuri-Mäkeläinen, J., \& Tammi, K. (2018). Overview of powertrain electrification and future scenarios for non-road mobile machinery. Energies, 11(5), 1184. https://doi.org/10.3390/en11051184

Lavin, A. (2015). A Pareto front-based multiobjective path planning algorithm. arXiv preprint, arXiv:1505.05947.

Lewis, P., Leming, M., Frey, H. C., \& Rasdorf, W. (2011). Assessing effects of operational efficiency on pollutant emissions of nonroad diesel construction equipment. Transportation Research Record: Journal of the Transportation Research Board, 2233(1), 11-18. https://doi.org/10.3141/2233-02

Li, D., \& Lu, M. (2016). Automated generation of work breakdown structure and project network model for earthworks project planning: a flow network-based optimization approach. Journal of Construction Engineering and Management, 143(1), 04016086.

https://doi.org/10.1061/(ASCE)CO.1943-7862.0001214

Li, H., \& Lei, Z. (2010). Implementation of Discrete-Event Simulation (DES) in estimating \& analyzing CO 2 emission during earthwork of building construction engineering. In 2010 IEEE 17th International Conference on Industrial Engineering and Engineering Management. Xiamen, China. https://doi.org/10.1109/ICIEEM.2010.5646619

Lin, B., \& Li, X. (2011). The effect of carbon tax on per capita CO2 emissions. Energy Policy, 39(9), 5137-5146. https://doi.org/10.1016/j.enpol.2011.05.050

Liu, C., An, X., Ahn, C. R., \& Lee, S. (2013). Integrated evaluation of cost, schedule and emission performance on rockfilled concrete dam construction operation using discrete event simulation. In Proceedings of the 2013 Winter Simulation Conference: Simulation: Making Decisions in a Complex World. Washington, DC, USA. https://doi.org/10.1109/WSC.2013.6721678

Love, B. J., \& Nejadhashemi, A. P. (2011). Water quality impact assessment of large-scale biofuel crops expansion in agricultural regions of Michigan. Biomass Bioenergy, 35(5), 22002216. https://doi.org/10.1016/j.biombioe.2011.02.041

Marshall, S. K., Rasdorf, W., Lewis, P., \& Frey, H. C. (2012). Methodology for estimating emissions inventories for commercial building projects. Journal of Architectural Engineering, 18(3), 251-260.

https://doi.org/10.1061/(ASCE)AE.1943-5568.0000073

Marzouk, M., \& Moselhi, O. (2003). A decision support tool for construction bidding. Construction Innovation, 3(2), 111-124. https://doi.org/10.1108/14714170310814882

Marzouk, M., \& Moselhi, O. (2004). Multiobjective optimization of earthmoving operations. Journal of Construction Engineering and Management, 130(1), 105-113. https://doi.org/10.1061/(ASCE)0733-9364(2004)130:1(105) 
Mawdesley, M., A-Jibouri, S., Askew, W., \& Patterson, D. (2002). A model for the automated generation of earthwork planning activities. Construction Innovation, 2(4), 249-268. https://doi.org/10.1108/14714170210814793

McMichael, A. J., Woodruff, R. E., \& Hales, S. (2006). Climate change and human health: present and future risks. The Lancet, 367, 859-869. https://doi.org/10.1016/S0140-6736(06)68079-3

Melanta, S., Miller-Hooks, E., \& Avetisyan, H. G. (2012). Carbon footprint estimation tool for transportation construction projects. Journal of Construction Engineering and Management, 139(5), 547-555. https://doi.org/10.1061/(ASCE)CO.1943-7862.0000598

Moselhi, O., \& Alshibani, A. (2009). Optimization of earthmoving operations in heavy civil engineering projects. Journal of Construction Engineering and Management, 135(10), 948-954. https://doi.org/10.1061/(ASCE)0733-9364(2009)135:10(948)

Nabaei, A., Hamian, M., Parsaei, M. R., Safdari, R., SamadSoltani, T., Zarrabi, H., \& Ghassemi, A. (2018). Topologies and performance of intelligent algorithms: a comprehensive review. Artificial Intelligence Review, 49(1), 79-103. https://doi.org/10.1007/s10462-016-9517-3

Nassar, K., \& Hosny, O. (2011). Solving the least-cost route cut and fill sequencing problem using particle swarm. Journal of Construction Engineering and Management, 138(8), 931-942. https://doi.org/10.1061/(ASCE)CO.1943-7862.0000512

Parente, M., Cortez, P., \& Correia, A. G. (2015). An evolutionary multi-objective optimization system for earthworks. Expert Systems with Applications, 42(19), 6674-6685. https://doi. org/10.1016/j.eswa.2015.04.051

Parente, M., Correia, A. G., \& Cortez, P. (2016). A novel integrated optimization system for earthwork tasks. Transportation Research Procedia, 14, 3601-3610. https://doi.org/10.1016/j.trpro.2016.05.428

Sanchez, A. X., Lehtiranta, L. M., \& Hampson, K. D. (2015). Use of contract models to improve environmental outcomes in transport infrastructure construction. Journal of Environmental Planning and Management, 58(11), 1923-1943. https://doi.org/10.1080/09640568.2014.969832

Shah, R. K., \& Dawood, N. (2011). An innovative approach for generation of a time location plan in road construction projects. Construction Management and Economics, 29(5), 435448. https://doi.org/10.1080/01446193.2011.563785

Shi, Q., Zuo, J., Huang, R., Huang, J., \& Pullen, S. (2013). Identifying the critical factors for green construction-an empirical study in China. Habitat International, 40, 1-8. https://doi.org/10.1016/j.habitatint.2013.01.003

Siami-Irdemoosa, E., \& Dindarloo, S. R. (2015). Prediction of fuel consumption of mining dump trucks: A neural networks approach. Applied Energy, 151, 77-84. https://doi.org/10.1016/j.apenergy.2015.04.064

Son, J., Mattila, K. G., \& Myers, D. S. (2005). Determination of haul distance and direction in mass excavation. Journal of Construction Engineering and Management, 131(3), 302-309. https://doi.org/10.1061/(ASCE)0733-9364(2005)131:3(302)

Szamocki, N., Kim, M., Ahn, C. R., \& Brilakis, I. (2019). Reducing greenhouse gas emission of construction equipment at construction sites: Field study approach. Journal of Construction Engineering and Management, 145(9), 05019012. https://doi.org/10.1061/(ASCE)CO.1943-7862.0001690

Trafikverket. (2017). Klimatkrav. https://www.trafikverket.se/fordig-i-branschen/miljo---for-dig-i-branschen/energi-och-klimat/klimatkrav/
Tuppadung, Y., \& Kurutach, W. (2011). Comparing nonlinear inertia weights and constriction factors in particle swarm optimization. International Journal of Knowledge-based and Intelligent Engineering Systems, 15(2), 65-70.

https://doi.org/10.3233/KES-2010-0211

UNFCCC. (2015). Adoption of the Paris agreement. Geneva: United Nations Office at Geneva. https://unfccc.int/resource/docs/2015/cop21/eng/109r01.pdf

Zhang, X., Wu, Y., Shen, L., \& Skitmore, M. (2014). A prototype system dynamic model for assessing the sustainability of construction projects. International Journal of Project Management, 32(1), 66-76.

https://doi.org/10.1016/j.ijproman.2013.01.009 